\title{
INEQUALITY, TRANSFERS, AND GROWTH: NEW EVIDENCE FROM THE ECONOMIC TRANSITION IN POLAND
}

\author{
Michael P. Keane and Eswar S. Prasad*
}

\begin{abstract}
This paper analyzes the evolution of inequality in Poland during the economic transition that began in 1989-1990. Using microdata from the Household Budget Surveys, we find that, after a brief spike in 1989 , income and consumption inequality actually declined to below pretransition levels during 1990-1992 and then increase d gradually, rising only moderately above pretransition levels by 1997 . In sharp contrast, inequality in labor earnings increased markedly and consistently throughout the 1990-1997 period. We find that social transfer mechanisms, including pensions, played an important role in mitigating increases in both overall inequality and poverty. We argue that, from a political economy perspective, transfer mechanism s were well designed to reduce political resistance to market-oriented reforms in the early years of transition, paving the way for rapid growth. Finally, we provide crosscountry evidence from the transition economies that is consistent with our interpretation of the Polish experience and is also consistent with recent work in growth theory suggesting that redistribution that reduces inequality can enhance growth.
\end{abstract}

\section{Introduction}

A MONG the most dramatic economic events of the early 1990s was the beginning of the process of transformation of countries in Eastern Europe from planned to market economies. These transition economies have had considerably different experiences in terms of the speed and success of transition and in terms of macroeconomic outcomes including output growth. But a widely held view is that, in all of these economies, the economic upheaval associated with the process of transition has led to substantial increases in inequality.

This view, as summarized by Milanovic (1998) and Aghion and Commander (1999), has been challenged in an important paper by Garner and Terrell (1998) who show that, in the Czech and Slovak republics, there has been only a moderate increase in inequality in the early years of transition. More importantly, Garner and Terrell conclude that government policies, in the form of social transfers, significantly dampened the increase in inequality. By contrast, Commander and Lee (1998) present evidence showing that social transfers may have actually exacerbated the rise in inequality in the Russian transition.

Received for publication November 9, 2000. Revision accepted for publication November 13, 2001.

* Yale University and International Monetary Fund, respectively.

We thank the staff at the Polish Central Statistical Office, especially Wiesław Łagodziński and Jan Kordos, for assistance with the data. We also thank Krzystof Przybylowski and Barbara Kamińska for excellent translations of the survey instruments and Branko Milanovic for generously sharing his cross-countr y data with us. This paper has benefited from the comments of two anonymous referees. We also received helpful comments on earlier versions of this paper from numerous colleagues including Mark De Broeck, Jennifer Hunt, Vincent Koen, Branko Milanovic, Michał Rutkowski, Adam Szulc, and seminar participants at Johns Hopkins, New York University, Stanford, CEMFI, CEEER, the World Bank, the IMF, and meeting s of the Econometric Society, the Royal Economic Society, and the European Economic Association. Financial support was provided by the National Council for Eurasian and East European Research.
In this paper, we provide new evidence that is relevant for this debate from Poland, which is one of the more successful transition countries. Using microdata from the Household Budget Surveys (HBS) conducted by the Polish Central Statistical Office (CSO), we examine the evolution of income and consumption distributions in Poland over the period 1985-1997. Our sample covers the first eight years of the economic transition that began with the so-called "big bang" reform of August 1989 to January 1990. ${ }^{1}$ Thus, we are able to trace out the time path of income and consumption inequality for an extended period both leading up to and following the "big bang." Although we highlight changes in aggregate measures of inequality such as Gini coefficients to compare our results with those for other countries, the microdata enable us to provide a more detailed characterization of changes in Polish income and consumption distributions and over a longer period than any previous study of transition economies.

Contrary to the conventional wisdom about the Polish transition, we find no evidence that income and consumption inequality increased in the early years of the transition. In fact, our preferred estimate of the Gini coefficient for the overall individual income distribution actually declined from 0.256 in 1988 to 0.230 in 1992 . It then began a gradual increase, reaching levels comparable to the pretransition period in 1994-1996 and then rising to 0.276 by 1997 . To put an increase of 0.020 in the income Gini coefficient in perspective, it is only two-thirds as much as the increase reported for the United States in the 1980s by Atkinson, Rainwater, and Smeeding (1995). Viewed another way, it still leaves Poland with a Gini value closer to those of Scandinavian countries (around 0.25) than that of the United States (0.41). (See World Bank (2000).)

However, we find that inequality in labor earnings increased steadily and substantially during the transition period of 1989-1997. In Poland, the increase in the Gini coefficient for labor earnings (0.046) was more than twice that of the Gini for overall income (0.020). Analysis of individual earnings data, also from the HBS, indicates that earnings differentials across education levels increased rapidly during the transition, reflecting sharp increases in education premia. But the premium for labor market experience

\footnotetext{
${ }^{1}$ The communist government ended food price controls as it left power in August 1989. The new Mazowiecki government implemented the Balcerowicz plan in January 1990, and this ended price controls on most products, leading to substantial inflation and changes in relative prices. Other aspects of the reforms, including reductions in state orders for manufacture d goods and restraints on credit for state-owned enterprises, along with external shocks such as increased import competition and the collapse of the CMEA trade bloc, contributed to large declines in real GDP (of $11.6 \%$ in 1990 and $7.0 \%$ in 1991, according to IMF estimates).
} 
fell sharply after the transition, and the position of older workers deteriorated relative to younger workers, consistent with the notion of rapid obsolescence of skills of older workers in a period of massive industrial restructuring.

Furthermore, although we find no evidence of increases in overall inequality, an analysis of the relative positions of different socioeconomic groups indicates that there were indeed winners and losers during transition. We find that social transfers played a key role in between-group income dynamics as well as in mitigating the increase in income inequality, particularly in the early phase of transition. A marked increase in the generosity of public sector pensions in 1991 led to a substantial exit of older workers from the labor force onto the pension rolls in 1991-1992 and improved the relative income position of pensioner-headed households. At the same time, other social transfers were increased from 3\% of GDP in 1989 to about 5\% by 1992 . Together, these changes were sufficient to counteract the increase in earnings inequality. As Dewatripont and Roland (1996) point out, such increases in transfers can be rationalized as necessary to achieve initial political support for the "big bang" reform strategy. From 1993 onward, growth in transfers was halted and overall inequality began to rise gradually.

A substantial proportion of transfers was in fact directed not towards households at the bottom of the income distribution but towards the middle class and, via the increased generosity of pensions, to older workers who were potentially big losers in terms of employment and earnings prospects during the transition. Although transfers may not have been well targeted from a welfare perspective, our results suggest that, from a political economy perspective, transfers may have been a critical component for ensuring social stability and setting the stage for rapid reforms, including enterprise restructuring, during the early years of the transition.

In the final part of the paper, we also provide crosscountry evidence on inequality, social transfers, and growth in the transition economies that is consistent with our interpretation of the Polish experience. Across fourteen countries for which we can observe Gini values both prior to and several years after the start of the transition (that is, in 1988-1989 and 1995-1997), the mean increase in the Gini is 0.095 , which is several times larger than that observed in Poland. In fact, Poland had the least growth in inequality among these countries but also experienced the fastest economic growth. We find that the correlation between growth and changes in inequality in transition economies has been strongly negative. This result holds up even when we control for a number of key factors that may help to explain growth, such as indicators of initial conditions and measures of policy reforms aimed at market-oriented liberalization.

The relationship between growth and inequality has been the subject of considerable debate in recent years. (See the survey by Aghion, Caroli, and García-Peñalosa (1999).) A traditional view is that higher inequality is associated with higher rates of growth. Kuznets (1955) presented evidence of a U-shaped relationship between inequality and per capita GNP, which he interpreted as evidence that inequality increases in the early stages of development and falls thereafter. ${ }^{2}$ But a newer body of empirical work suggests a negative correlation between inequality and subsequent economic growth (Persson \& Tabellini, 1994). ${ }^{3}$ Recent work in growth theory has rationalized this finding by showing that redistributive transfers can enhance growth in an environment characterized by significant liquidity constraints. ${ }^{4}$ Also, in a political economy model, Alesina and Rodrik (1994) show that income redistribution can enhance growth by reducing political support for taxation of capital. And Perotti (1996) finds empirical support for the view that redistribution can enhance growth by fostering sociopolitical stability.

The Polish experience is relevant to this literature on inequality, redistribution, and growth. In Poland, social (cash) transfers as a percent of GDP averaged $17.7 \%$ during 1990-1997, the highest level in any transition country. We find that this high level of transfers helped Poland maintain the smallest increase in inequality among the transition economies. In fact, Gomułka (1998) refers to a "Polish model" of transition "distinguished by an exceptionally large volume of social transfers, especially ... pensions" that "helped to reduce the social cost of reform, but is inhibiting Poland's ability to sustain rapid growth" (p. 166). This theme- that the level of transfers in Poland will hinder future growth-has been sounded by many authors, including OECD (1997), but such predictions have yet to be borne out. In 1998-1999, Poland continued to experience morerapid growth than any of the other transition countries in our sample.

Given recent developments in growth theory, it is intriguing to speculate that a high level of transfers may actually have helped rather than hindered economic growth in Poland, especially in the early stages of transition. We conclude by presenting some suggestive cross-country evidence indicating that the relationship between social transfers and growth in transition economies has in fact been positive,

\footnotetext{
${ }^{2}$ A standard argument is that inequality fosters growth in environments characterize d by liquidity constraints, because only wealthy individuals can bear the sunk costs of starting industrial activities. Evans and Jovanovic (1989) provide evidence that capital market constraints affect the decision to become an entrepreneur in the United States.

${ }^{3}$ The evidence remains inconclusive, however. For instance, Forbes (2000) reports a positive correlation between income inequality and subsequent economic growth whereas Banerjee and Duflo (2000) find no relationship.

${ }^{4}$ For instance, Galor and Zeira (1993) present a model with borrowing constraints in which individual productivity is a concave function of human capital and show that redistribution of wealth from the rich to the poor enhances growth because the poor have a higher marginal productivity of investment. Related results have been obtained by Banerjee and Newman (1993), Aghion and Bolton (1997), and Benabou (1996).
} 
which is similar to Perotti's 1996 finding for a different and larger sample of countries.

\section{Review of Prior Research on Inequality in Poland}

There exist a few other studies that have examined income inequality in Poland during the transition, but they report quite contradictory results (this despite the fact that they all use income data derived from the HBS and look at Gini coefficients for the individual income distribution, assigning to each individual the per capita income for the household in which he/she resides). For instance, based on statistics computed by the CSO, OECD $(1997$, p. 86) reports that the Gini for Poland was 0.25 in 1989, dropped to 0.23 in 1990, and then rose substantially to 0.26 in 1991 and to 0.29 by 1993 . It then remained fairly stable in the $0.29-0.30$ range through 1996. In contrast, Gorecki (1994) also finds a drop in inequality from 1989 to 1990, but finds no evidence of a subsequent increase in 1991. Milanovic (1999), using published data on income deciles for years prior to 1993 and the HBS microdata for 1993-1995, reports that the Gini fell from 0.260 in 1989 to 0.247 in 1991. Like the OECD, he reports a very large jump in the Gini in 1993 to 0.298 . But, in contrast to the OECD, his figures suggest that the Gini continued to rise very substantially after 1993, reaching 0.356 in $1995 .^{5}$

To summarize, all three studies suggest that income inequality declined from 1989 to 1990 . The CSO-OECD figures imply a very large increase in income inequality in 1991, whereas the Milanovic and Gorecki figures do not show this. The CSO-OECD (1997) and Milanovic (1999) figures are consistent, however, in implying that large increases in inequality occurred between 1992 and 1993. But the CSO-OECD figures indicate that inequality then stabilized, whereas the Milanovic figures imply that it grew substantially again in 1994-1995.

What can account for this wide divergence in reported results? A problem with these studies is that they do not use the actual HBS microdata for the period prior to 1993. Rather, for that period, the Gini values in these studies were approximated using aggregate data on quantiles of the income distribution published by the CSO in the annual publication Budzety Gospodarstw Domowych. The accuracy of these approximations is certainly an issue.

But a more serious problem is that, in 1993, the CSO switched from quarterly to monthly data collection. Because

\footnotetext{
${ }^{5}$ Figures in European Bank for Reconstruction and Development (2000) are consistent with the OECD figures in that they imply that the Gini plateaued around 0.30 from 1995 onward. World Bank (1999, 2000) reports per capita income Ginis of 0.272 in 1992 and 0.329 in 1996. This stands between the OECD and Milanovic (1999) calculation s in terms of the rise in inequality over this period. Torrey, Smeeding, and Bailey (1999), using a sample that constitutes about $45 \%$ of the full HBS sample now available through the Luxembourg Income Survey (LIS) for selected years, report income Ginis of 0.217 for 1987, 0.248 for 1990, and 0.243 for 1992. The LIS's attempt to use a standardize d definition of income across country surveys could account for part of the difference between their results and those of other authors and the CSO.
}

income is typically more variable at the monthly than the quarterly frequency, this shift alone would have created a substantial increase in cross-sectional income inequality and in the Gini coefficient. We will argue that the switch to monthly income reporting accounts for most of the increase in inequality between 1992 and 1993 reported in both OECD (1997) and Milanovic (1999). In the appendix, we develop a technique for adjusting the 1993-1997 income and consumption data for the increased variability that may be attributable solely to the shift from quarterly to monthly reporting.

Another potential problem with previous studies is that the income statistics reported by the CSO, as well as those reported by other former communist countries, differ in a number of important ways from economically meaningful measures of income. The official statistics appear to reflect total revenues or "inflows" because they include loans, dissaving, and cash holdings at the beginning of the survey period. For farmers, income includes gross, rather than net, farm revenues. This is an important issue as approximately one-fifth of Polish households are either farm households or mixed worker-farmer households. Access to the microdata enables us to make the necessary adjustments to obtain more-meaningful measures of income (by excluding nonincome revenue items and by calculating net farm income) as well as consumption.

In summary, our study is unique in that it is based on the HBS microdata for a long sample period, extending from five years prior to the "big bang" to eight years after. The microdata enable use to make several improvements over previous studies, including use of microdata for the pre1993 period, correction of the income and consumption definitions, and adjustment for the change in sampling frame in 1993.

\section{The Household Budget Surveys}

The CSO has been collecting detailed microdata on household income and consumption at least since 1978, using fairly sophisticated sampling techniques. In the HBS, the primary sampling unit is the household. A two-stage geographically stratified sampling scheme is used in which the first-stage sampling units are the area survey units and the second-stage units are individual households. In our empirical work, we use sampling weights to maintain the representativeness of the sample. Households were surveyed for a full quarter (through 1992) or for a full month (from 1993 onward) to monitor their income and spending patterns. Supplementary information on household demographics, durable good holdings, and so on is collected from the same households once every year. The typical sample size is approximately 25,000 households per year. The CSO uses the data obtained from these household surveys to create aggregate tabulations that are then presented in their monthly and annual statistical bulletins, or surveys. 
The HBS contains detailed information on sources and amounts of income for households as well as individuals within each household. Total income is broken down into four main categories: labor income (including wages, salaries, and nonwage compensation), pensions, social benefits and other transfers, and other income. Social benefits include income from unemployment benefits that were introduced in late 1989. A key point is that the data include measures of the value of in-kind payments from employers to workers, which have been an important part of workers' compensation in Poland and other transition economies. For farm households, farm income and expenditures, as well as own consumption of the farm's produce, are also reported. There were no taxes on personal income until 1992. After that year, we use net incomes in the analysis. The HBS also contains detailed information on consumption. For this study, we aggregate the consumption data and examine only total and nondurables consumption.

In the immediate aftermath of the big bang, Poland experienced rapid inflation and substantial relative price changes. Using information from various CSO publications and IMF data bases, we extracted quarterly and, for 19931997, monthly time series on various aggregate and disaggregate price indices. For the results reported in this paper, we used the aggregate CPI as the price deflator. Our ability to match the frequency of the price data to the frequency of the survey data on income and consumption is important in the context of the large price changes that occurred during the transition. We also experimented with using regional and group-specific price indices as well as disaggregated price data that matched our disaggregated consumption data (sixteen categories). These alternative price deflators made little difference to our main results.

Two important changes were made to the HBS survey design in 1993. We have already noted the change to monthly income and consumption reporting. The other major change was an attempt to obtain a more representative sample of the self-employed. This group's size is believed to have increased markedly since the transition began. In the next section, we examine the extent to which possible underrepresentation of the self-employed in the HBS data during the period 1990-1992 may have led to understatement of the extent of inequality in those years.

Table 1 reports sample means for some of the variables used extensively in our analysis of inequality. ${ }^{6}$ Two interesting features are that the average share of income from transfers and the share of pensioner-headed households increase markedly after the transition. (We discuss this in greater detail later.) The demographic characteristics of households and household heads remain quite stable during and after the transition. The means of the education dummies indicate a small increase in average levels of educa-

\footnotetext{
${ }^{6}$ Note that the sample size falls in 1992. In that year, half of the total sample was used to test the new monthly survey; these data were considere d unreliable and not made available to us.
}

tional attainment of household heads in the 1990s (a similar increase occurs in the general population as well).

\section{Inequality}

In this section, we examine various aspects of inequality in Poland over the period 1985-1997. For the years 19931997, we use the income and consumption measures that are adjusted (using the procedure described in the appendix) for the increase in idiosyncratic variance that occurred with the shift to a monthly reporting period. The measures of inequality we examine are based on the distribution of individual income or consumption, unless explicitly noted otherwise. A key issue in inequality measurement is how to account for household composition and economies of scale when measuring household well-being or when assigning individual income or consumption levels to household members. Most prior studies of income inequality in Poland and other transition economies have simply assigned the per capita household income to each member of a household prior to measuring inequality in individual income. ${ }^{7}$

In an earlier paper (Keane \& Prasad, 1999), we constructed food share (FS)-based equivalence scales for Poland using the Engel (1895) method, which assumes that two households with different demographic composition are equally well off at income levels that enable them to have equal food shares (ratio of expenditure on food to total expenditure on nondurables). The estimated equivalence scales exhibited somewhat greater household economies of scale than those typically used for western countries. We next report our key results based on a number of alternative equivalence scales to ensure that our results are not sensitive to the choice of scale. Besides our own FS scale, we also use the OECD scale, the McClements (1977) scale (commonly used in Britain), and the simple per capita scale. Appendix table A1 shows values of these equivalence scales for a representative set of household types.

\section{A. Measures of Overall Inequality}

We first examine the evolution of summary measures of overall inequality. In all cases, we examine the distribution of individual income (or consumption), assigning to each individual the per equivalent (or per capita) income for the household in which the person resides. Table 2 reports Gini coefficients based on per capita incomes and incomes adjusted by the FS equivalence scale. The results in this table highlight the importance of adjusting for the change in survey frequency in 1993. Without this adjustment, for instance, the increase in the per capita income Gini from

\footnotetext{
${ }^{7}$ One exception is the paper by Garner and Terrell (1998) that uses equivalence scales. To the extent that there are household economies of scale, using per capita household income will exaggerate the well-being of people in smaller households, and, to the extent that adults have greater expense s than do children, use of per capita income will understate the well-being of people in households with many children.
} 
Table 1.-SAmple Means for Selected Years

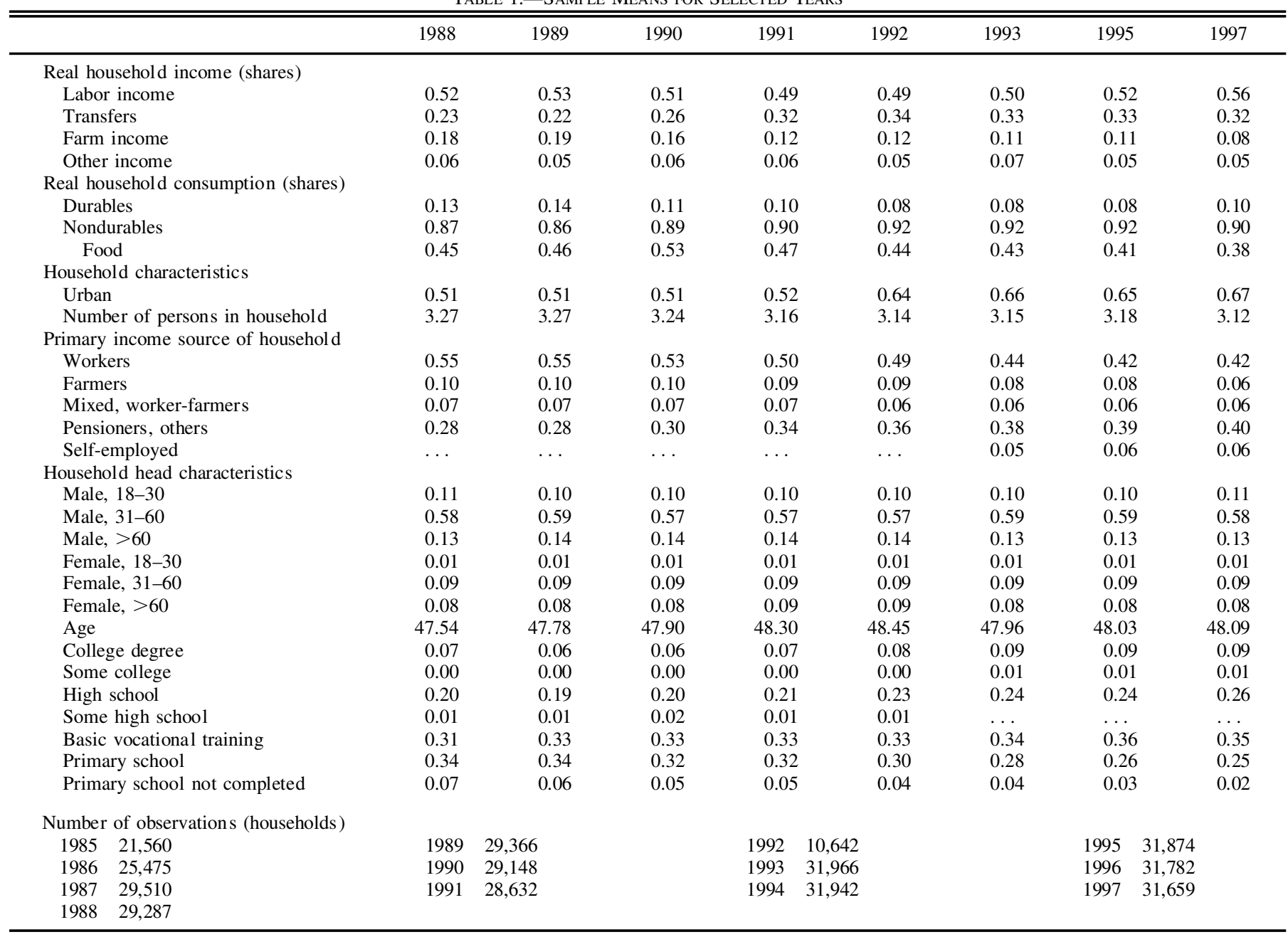

The components of income and consumption are shown as (mean) shares of total income and consumption, respectively.

1992 to 1993 is 0.045 , which is far larger than the estimated increase of 0.021 that we obtain using the adjusted data. Similarly, without the adjustment, the Ginis based on the FS equivalence scale would markedly overstate the increase in inequality that occurred between 1992 and 1993 (that is, a Gini increase of 0.046 versus 0.018 ). We use adjusted income and consumption measures for 1993-1997 in all of the remaining analysis.

In table 2, we also examine the Ginis with adjusted income but excluding the self-employed in 1993-1996. The inclusion of the self-employed makes only a small difference to either set of Ginis and suggests that underrepresentation of

Table 2.-EFfects of Changes in Survey in 1993 on Gini Coefficients for Income

\begin{tabular}{|c|c|c|c|c|c|c|c|c|c|c|c|c|c|}
\hline & 1985 & 1986 & 1987 & 1988 & 1989 & 1990 & 1991 & 1992 & 1993 & 1994 & 1995 & 1996 & 1997 \\
\hline & \multicolumn{13}{|c|}{ Per Capita Income Ginis } \\
\hline $\begin{array}{l}\text { Baseline } \\
\text { Alternative Ginis for } 1993-1997\end{array}$ & 0.270 & 0.274 & 0.270 & 0.272 & 0.278 & 0.271 & 0.266 & 0.264 & 0.285 & 0.298 & 0.294 & 0.301 & 0.319 \\
\hline Without residual adjustment & & & & & & & & & 0.309 & 0.323 & 0.318 & 0.327 & 0.339 \\
\hline \multirow[t]{2}{*}{ Excluding self-employed } & \multirow{2}{*}{\multicolumn{13}{|c|}{ Food-Share Based Equivalence Scale }} \\
\hline & & & & & & & & & & & & & \\
\hline Baseline & 0.252 & 0.254 & 0.246 & 0.256 & 0.263 & 0.250 & 0.235 & 0.230 & 0.248 & 0.262 & 0.255 & 0.265 & 0.276 \\
\hline Alternative Ginis for $1993-1997$ & & & & & & & & & & & & & \\
\hline Without residual adjustment & & & & & & & & & 0.276 & 0.292 & 0.284 & 0.296 & 0.304 \\
\hline Excluding self-employed & & & & & & & & & 0.243 & 0.257 & 0.250 & 0.261 & 0.274 \\
\hline
\end{tabular}

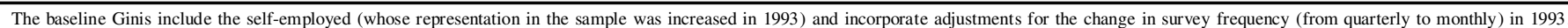
The procedure for adjusting the income data for 1993-1997 is described in the appendix. 
TABLE 3.-Poland: Measures of Inequality, 1985-1997

\begin{tabular}{|c|c|c|c|c|c|c|c|c|c|c|c|c|c|}
\hline & 1985 & 1986 & 1987 & 1988 & 1989 & 1990 & 1991 & 1992 & 1993 & 1994 & 1995 & 1996 & 1997 \\
\hline & \multicolumn{13}{|c|}{ Gini Coefficients } \\
\hline \multicolumn{14}{|l|}{ Total income } \\
\hline Food-share based eqv. scale & 0.252 & 0.254 & 0.246 & 0.256 & 0.263 & 0.250 & 0.235 & 0.230 & 0.248 & 0.262 & 0.255 & 0.265 & 0.276 \\
\hline McClements equivalence scale & 0.249 & 0.253 & 0.246 & 0.254 & 0.261 & 0.249 & 0.238 & 0.234 & 0.253 & 0.266 & 0.259 & 0.270 & 0.282 \\
\hline OECD equivalence scale & 0.253 & 0.257 & 0.250 & 0.256 & 0.264 & 0.253 & 0.242 & 0.238 & 0.257 & 0.271 & 0.264 & 0.275 & 0.286 \\
\hline Per capita & 0.270 & 0.274 & 0.270 & 0.272 & 0.278 & 0.271 & 0.266 & 0.264 & 0.285 & 0.298 & 0.294 & 0.301 & 0.319 \\
\hline Income excluding transfers & 0.373 & 0.375 & 0.368 & 0.385 & 0.384 & 0.389 & 0.404 & 0.416 & 0.416 & 0.437 & 0.432 & 0.448 & 0.451 \\
\hline \multicolumn{14}{|l|}{ Nondurables consumption } \\
\hline Food-share based eqv. scale & 0.196 & 0.200 & 0.205 & 0.211 & 0.219 & 0.209 & 0.208 & 0.205 & 0.222 & 0.228 & 0.222 & 0.227 & 0.235 \\
\hline McClements equivalence scale & 0.197 & 0.202 & 0.208 & 0.214 & 0.220 & 0.210 & 0.213 & 0.212 & 0.229 & 0.234 & 0.229 & 0.233 & 0.242 \\
\hline OECD equivalence scale & 0.200 & 0.207 & 0.212 & 0.217 & 0.224 & 0.214 & 0.218 & 0.217 & 0.234 & 0.239 & 0.234 & 0.239 & 0.247 \\
\hline Per capita & 0.222 & 0.229 & 0.236 & 0.239 & 0.242 & 0.235 & 0.245 & 0.249 & 0.262 & 0.268 & 0.264 & 0.268 & 0.277 \\
\hline \multirow[t]{2}{*}{ Total consumption } & 0.230 & 0.234 & 0.239 & 0.244 & 0.258 & 0.241 & 0.233 & 0.227 & 0.247 & 0.254 & 0.247 & 0.262 & 0.271 \\
\hline & \multicolumn{13}{|c|}{ Half the Square of the Coefficient of Variation } \\
\hline Total income & 0.085 & 0.090 & 0.085 & 0.091 & 0.105 & 0.086 & 0.079 & 0.077 & 0.097 & 0.103 & 0.096 & 0.105 & 0.112 \\
\hline Nondurables consumption & 0.066 & 0.068 & 0.070 & 0.074 & 0.081 & 0.068 & 0.072 & 0.068 & 0.088 & 0.093 & 0.085 & 0.091 & 0.099 \\
\hline \multirow[t]{2}{*}{ Income excluding transfers } & 0.184 & 0.190 & 0.186 & 0.203 & 0.210 & 0.207 & 0.230 & 0.244 & 0.265 & 0.281 & 0.278 & 0.294 & 0.306 \\
\hline & \multicolumn{13}{|c|}{ Mean Log Deviation } \\
\hline Total income & 0.075 & 0.079 & 0.077 & 0.078 & 0.087 & 0.075 & 0.071 & 0.069 & 0.079 & 0.086 & 0.081 & 0.086 & 0.093 \\
\hline Nondurables consumption & 0.060 & 0.062 & 0.064 & 0.067 & 0.074 & 0.062 & 0.064 & 0.064 & 0.067 & 0.064 & 0.056 & 0.055 & 0.082 \\
\hline \multirow[t]{2}{*}{ Income excluding transfers } & 0.224 & 0.214 & 0.213 & 0.221 & 0.244 & 0.247 & 0.268 & 0.278 & 0.404 & 0.357 & 0.333 & 0.317 & 0.444 \\
\hline & \multicolumn{13}{|c|}{ Within-Group Gini Coefficients } \\
\hline Workers & 0.186 & 0.192 & 0.191 & 0.189 & 0.208 & 0.211 & 0.208 & 0.211 & 0.222 & 0.234 & 0.228 & 0.240 & 0.248 \\
\hline Farmers & 0.475 & 0.483 & 0.478 & 0.496 & 0.440 & 0.420 & 0.366 & 0.321 & 0.313 & 0.362 & 0.341 & 0.366 & 0.414 \\
\hline Mixed, worker-farmers & 0.272 & 0.279 & 0.276 & 0.285 & 0.271 & 0.253 & 0.229 & 0.220 & 0.223 & 0.234 & 0.244 & 0.252 & 0.267 \\
\hline Pensioners, other & 0.211 & 0.212 & 0.203 & 0.205 & 0.214 & 0.206 & 0.210 & 0.203 & 0.225 & 0.231 & 0.226 & 0.228 & 0.240 \\
\hline Workers (labor income only) & 0.237 & 0.243 & 0.240 & 0.252 & 0.262 & 0.268 & 0.278 & 0.289 & 0.285 & 0.292 & 0.288 & 0.295 & 0.298 \\
\hline
\end{tabular}

The inequality measures shown here are for the individual distributions of income and consumption. Household income and consumption are adjusted using the food
otherwise) and allocated equally to individuals in the household. Income and consumption data for 1993-1997 are adjusted for the change in survey frequency.

the self-employed in 1990-1992 is unlikely to have resulted in a significant downward bias in Gini coefficients for those years. ${ }^{8}$ Henceforth, we focus on results including the selfemployed, recognizing that this generates a bit of a spurious jump in inequality in 1992-1993 due to the slight change in sample composition.

Table 3 first reports Gini coefficients based on four alternative equivalence scales. Note that the three scales that account for household economies of scale (FS, McClements, and OECD) produce very similar Ginis, typically differing only in the third decimal place. The Ginis based on all four scales indicate that inequality increased in 1989 compared to the level in 1985-1988, but that inequality returned to pretransition levels in 1990, and continued to decline in 1991-1992. The Gini based on the FS scale shows the sharpest decline in inequality in 1989-1992 (from 0.263 to 0.230 ), and the Gini based on per capita income shows the smallest decline (from 0.278 to 0.264 ), but Ginis based on all four scales exhibit the same basic pattern.

In short, inequality spiked in the immediate aftermath of the big bang but, by 1992, it was no higher than the levels

\footnotetext{
${ }^{8}$ Because this group covers household heads engaged in a wide variety of businesses, households in this group do not systematically have higher income levels than the sample averages. In fact, the distribution of income among the self-employe $d$ is just slightly more unequal than for the general population.
}

seen before the transition. Starting in 1993, however, inequality begins to rise and, by 1997, is at a level higher than the peak attained in 1989. This pattern is robust to the choice of equivalence scale. It is important to note, however, that the increase in inequality even by 1997 is hardly dramatic. For example, the Gini based on the FS equivalence scale rises from 0.256 in 1988 (the year before the transition) to 0.276 in 1997 . This increase of 0.020 is smaller than the increase of 0.03 reported for the United States in the 1980s by Atkinson et al. (1995), or the increase from 0.326 to 0.361 reported for the United Kingdom from 1986 to 1991 in World Bank (1999, 2000).

All of our Gini coefficients, regardless of the equivalence scale used, imply a much smaller increase in inequality than that implied by official CSO-OECD (1997) figures for 1989-1996 on which the conventional wisdom about the sharp increase in inequality after the transition appear to be based. Those figures imply that the Gini coefficient for per capita income rose from 0.249 in 1989 to 0.290 in 1993. In the same period, our per capita Ginis are rather flat, rising only from 0.278 to 0.282 . For 1996 , the OECD reports a Gini value of 0.300 whereas our value is 0.301 . During 1989-1996 (the longest period for which we can compare results), the OECD figures imply an increase of 0.051 whereas our figures imply an increase of only 0.023 . Thus, the OECD figures imply an increase in inequality in Poland 
during the transition that is very large by historical standards, but our figures imply an increase that is substantially smaller. ${ }^{9}$ Furthermore, our results using the FS scale, which we consider more reliable, imply essentially no increase in inequality over the 1989-1996 period (that is, the Gini changes from 0.263 to 0.265 ).

We also examined inequality based on income net of transfers (table 3, row 5). ${ }^{10}$ Interestingly, this reveals a very different picture. The Gini coefficient for income excluding transfers increased by 0.066 from 1988 to 1997, more than three times the increase in the Gini for overall income. Thus, it appears that transfers played a crucial role in inequality dynamics after the transition. (We later investigate this in greater detail.)

Rows 6 through 10 of table 3 report results for consumption inequality (using, as noted earlier, adjusted consumption data for 1993-1997). Consumption is a better measure of welfare than income, particularly as measures based on income could overstate inequality because they may reflect idiosyncratic income shocks that could be smoothed by households. As expected, the Gini coefficients for nondurables consumption are lower than those for income. Nevertheless, independent of the choice of equivalent scale, they show a pattern of changes in inequality almost identical to that based on income. Using total consumption reveals a similar picture.

To examine whether our main results were sensitive to the choice of inequality measure, we also computed two other scalar measures of inequality: the mean log deviation (MLD) and a monotonoic transform of the coefficient of variation $(\mathrm{CV})$. We report these inequality measures in the middle panels of table 3 to determine if they tell a consistent story. In fact, they do. When we use either income or nondurables consumption, these measures also show an upward spike in 1989, followed by a decline in 1990-1992 to below the pretransition level, and a subsequent steady increase in 1993-1997 to a level modestly above that in the pretransition period.

All three measures of inequality-the Gini coefficient, $\mathrm{CV}$, and MLD—show far greater increases in inequality when we look at income net of transfers rather than total income. This pattern is particularly interesting in the case of the CV measure, which is most sensitive to changes at the

\footnotetext{
${ }^{9}$ Note that, in the 1990s, our Ginis are closer to those computed by the CSO. In Keane and Prasad (2001), we describe a detailed attempt we made to reconcile our Gini coefficients for earlier years with the CSOOECD figures, which are also purportedly based on the HBS data. The differences can, to a large extent, be attributed to (i) the CSO's use of "revenues" rather than incomes in earlier years, (ii) use of grouped data in calculating Ginis (in the 1980s, tabulated decile groups were used, with all individuals in a given decile group being ascribed the mean income level within that decile; in recent years, percentile groups have been used), and (iii) the apparent inconsistent use of equivalence scales over time (this is based on private correspondence with the CSO)

${ }^{10}$ Because transfers tend to be stable over time, the adjustment factors (to adjust for the change in survey frequency in 1993) for income net of transfers were nearly identical to those we computed for income including transfers.
}

high end of the distribution. This result stems from the fact that transfers in Poland are focused not only at the low end of the income distribution but extend well into the high end. (We give more details on the targeting of transfers.)

To summarize, we find no evidence to support the view, based on official statistics, of a sharp increase in total income inequality following the transition in Poland. Our results also differ markedly from the OECD-CSO figures in terms of the timing of changes in inequality. Those figures imply that inequality grew tremendously from 1989 to 1993, and that it then stayed rather flat through 1996. Our results indicate that inequality actually fell from 19891992, but we find that inequality rose noticeably after 1993 and, especially, in 1996 and 1997. Thus, we find that most of the increase in inequality occurred several years after the big bang, and long after the OECD-CSO figures imply the increase had already ceased.

This difference in timing has important implications for the interpretation of what occurred during the transition. The OECD-CSO figures for Poland and comparable figures for other transition economies (Milanovic, 1999) are often viewed as evidence that marked increases in inequality are an inevitable concomitant of the process of transition to a market economy. Our results, however, indicate that the changes in inequality during the first seven years of the transition in Poland were quite modest. Thus, our results suggest that changes in inequality during transition may not be inevitable but, rather, may result from particular policy choices. Later in the paper, we discuss in more detail the role of social transfer policies in inequality dynamics.

Because our results concerning the evolution of inequality over time were not sensitive to the choice of a particular equivalence scale, we use only the FS scale in all further analysis. $^{11}$

\section{B. Quantile Ratios}

In this section, we examine income inequality by looking at quantile ratios. Unlike the scalar inequality measures considered thus far, this allows us to consider changes in inequality in different parts of the distribution. Figure 1 plots the 90-10 and 75-25 quantile ratios for each year over the sample period. The quantiles for individuals were calculated using real household income and nondurable consumption, both adjusted using the FS equivalence scale. The quantile ratios reveal some interesting patterns. After a brief spike in 1989, the 90-10 quantile ratio falls back to its pretransition level before gradually increasing in the mid1990s. However, note that the cumulative increase in the 90-10 ratio from the period 1985-1988 through 1997 is only about 0.20 , which is hardly a substantial increase. To put this in perspective, Gottschalk and Smeeding (1997) report

\footnotetext{
${ }^{11}$ We recomputed many of the later results in the paper using different equivalence scales. Although the levels of inequality were slightly affected by the choice of equivalenc e scale, as is the case in table 3 , patterns of the evolution of inequality over time were robust to this choice.
} 


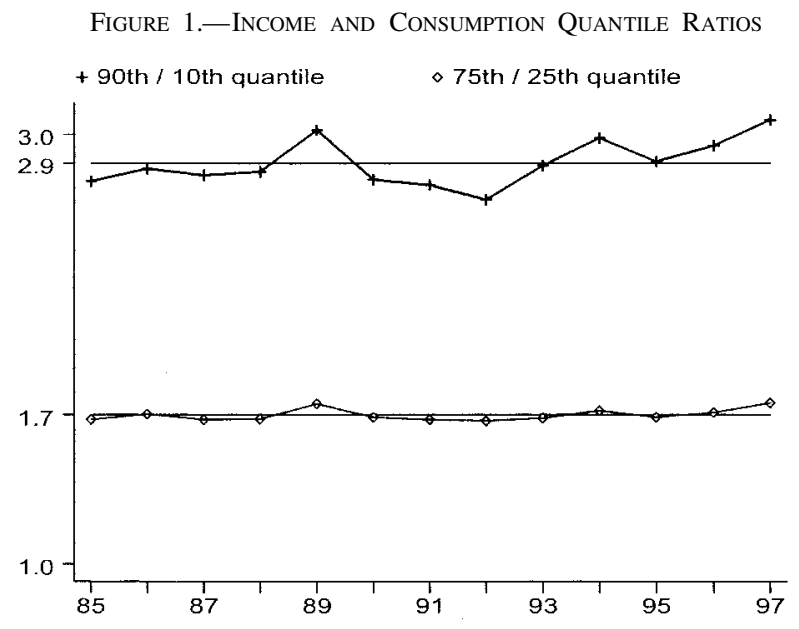

Ratios of Upper to Lower Quantiles: Income

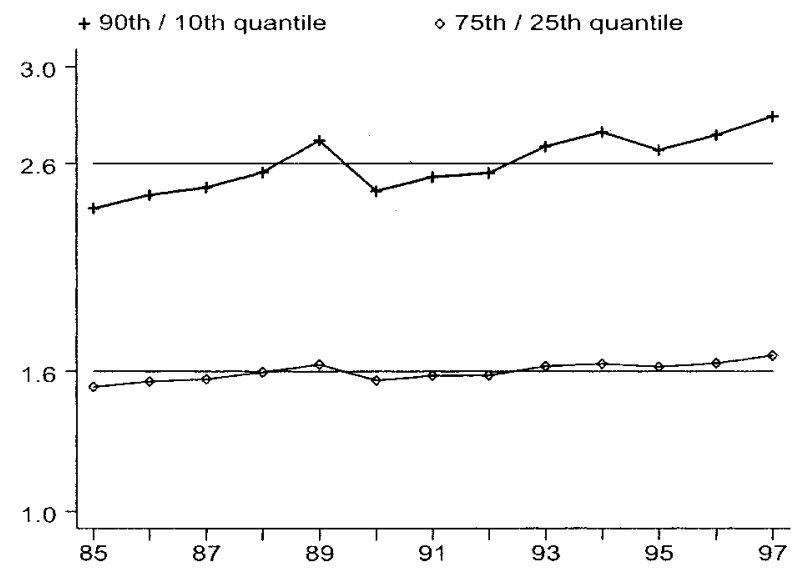

Ratios of Upper to Lower Quantiles: Consumption

a much greater increase of 1.04 (from 4.75 to 5.79 ) in the 90-10 ratio for the United States from 1980 to 1990. The 90-10 ratio for consumption follows a pattern very similar to that of the income ratio over the period 1988-1997 (although, for reasons that are not clear, it exhibits an upward trend prior to the transition). The 75-25 quantile ratios for income and consumption are essentially unchanged over the sample period, indicating even greater stability in the middle part of these distributions. We also examined finer breakdowns of the 90-10 and 75-25 quantile ratios (for example, the 90-50 and 50-10 quantiles ratios) and found that inequality was equally distributed above and below the median and that there were no significant changes in patterns of inequality that could be detected using these finer breakdowns of the data.

\section{Kernel Density Estimates of Income and Consumption Distributions}

To obtain a visual representation of changes in the shape and features of the entire distribution, we now examine kernel density estimates of household income and consump- tion distributions. Figure 2 (top panel) presents kernel density estimates for real household income for the years 1988, 1992, 1993, and 1995. ${ }^{12}$ The density is calculated at the same 200 income points for all four years, and the first 125 are plotted in the figure. This covers at least $98 \%$ of the households in all four years. Figure 4 (lower panel) also contains kernel density estimates for real household nondurable consumption for the same four years. Reflecting the more compact distribution of consumption, the first 75 points cover more than $99 \%$ of the households.

The change in the shape of the densities between the year 1988 and selected years after the big bang is striking. Much of the change simply reflects the decline in mean income and consumption following the big bang. However, the change in shape observed in figure 2 is not due simply to a contraction of the mean. To see this, consider taking the distribution for 1991 and multiplying all of the income figures by the ratio of mean income in 1988 to that in 1991 . Such a transformation will preserve relative inequality measures, while equating mean income in 1991 with that in 1988. This enables us to directly compare the shapes of the distributions, abstracting from mean differences. The 1988 income density and the transformed densities for 1991 and also for 1995 are plotted together in figure 3 (the vertical lines indicate the mean).

The most prominent features of figure 3 are that, in moving from 1988 to 1991, the mass in the left tail is reduced, and the distribution becomes more peaked around the mode. This accounts for the declines in the Gini measures noted previously. A key aspect of what happened during the transition becomes apparent if one compares the top panels of figures 2 and 3. In figure 2, we see that, as the overall income distribution shifted left, there was a support area at about 34,000 to 58,000 zlotys (prices indexed to 100 in 1992Q4) below which household income tended not to fall. Because of the drop in mean real income from 1988 to 1991 , the ratio of this support level to mean income increased. In figure 3, this has the effect of shifting to the right the fat part of the left tail of the scale-adjusted income distribution.

We investigated the income sources of households with real income in the 34,000-58,000 zloty range, and found that these households receive more than $80 \%$ of their income from pensions (80.5\% in 1988 and $82.2 \%$ in 1991). These percentages drop off quickly as household income rises above the 58,000 zloty level. The percentage of total household income for all households coming from pensions was $16.8 \%$ in 1988 and $26.8 \%$ in 1991 . Thus, the households with income in the support area of about 34,00058,000 zlotys got a far higher share of income from pensions than did the typical household. Furthermore, it is important to note that, although mean real household income fell from 178,969 zloty in 1988 to 131,563 zloty in

\footnotetext{
${ }^{12}$ An Epanechnikov kernel with a bandwidth of 4,000 was used for the kernel density estimation. No adjustment was made for household size.
} 
Figure 2.-Kernel Density Estimates
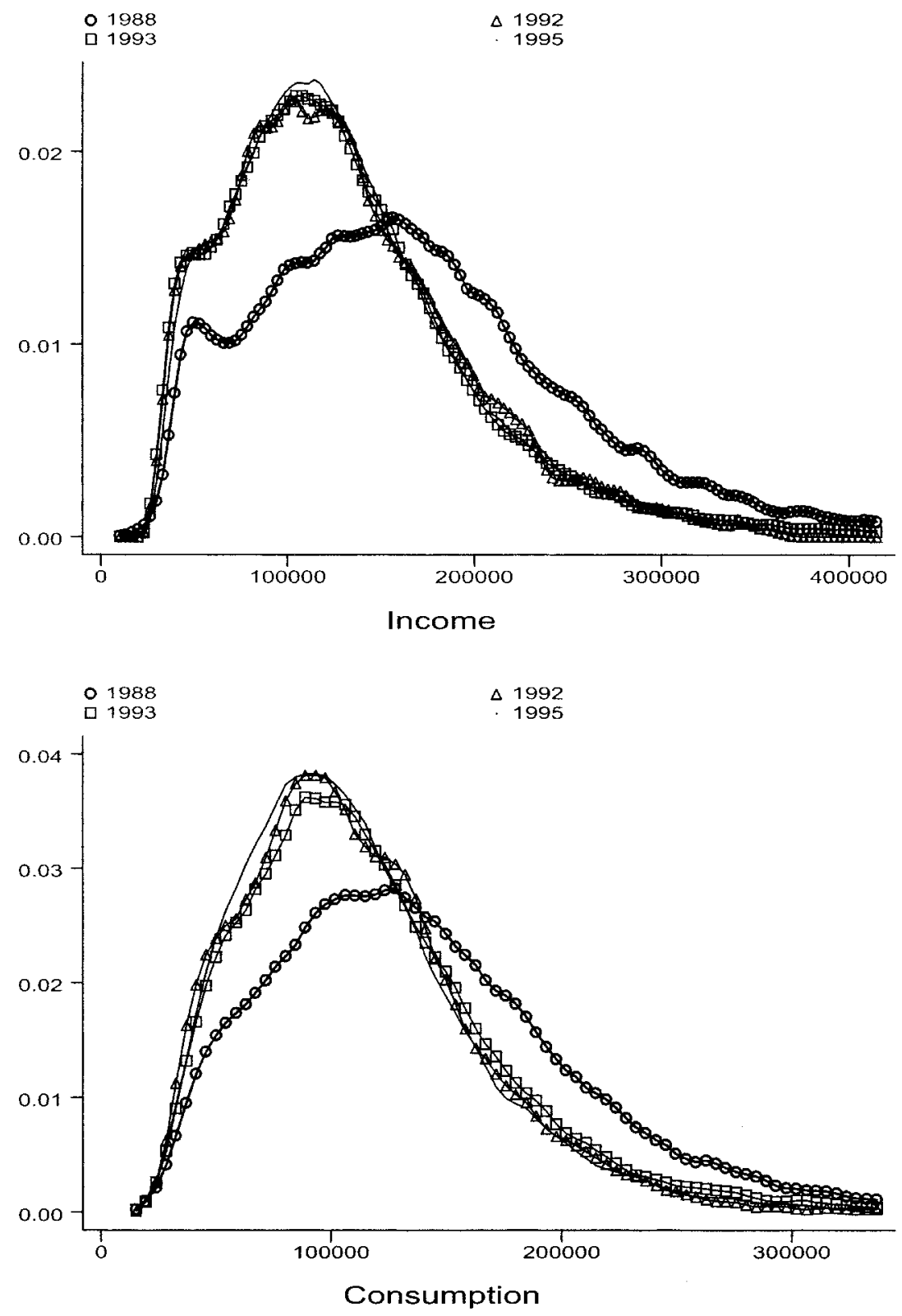

1991 , the mean real pension actually rose from 29,811 to 35,258 . This resulted from legislation that took effect in 1991 that made pensions substantially more generous. Hence, it is clear from our results that the new pension law helped shift the fat part of the left tail of the income distribution to the right and that this contributed importantly to the reductions in inequality measures that we have noted. ${ }^{13}$ The lower panel of figure 3 , which compares the adjusted distributions for 1991 and 1995, shows that this effect was further accentuated through 1995.

\footnotetext{
${ }^{13}$ It is also worth noting that the fraction of households headed by pensioners (and other social benefit recipients) increased from about $28 \%$ in the 1985-1989 period to $36 \%$ in 1992. Opting for the more-generou s pensions was apparently an attractive option for workers who did not fare well in the transition. We return to this issue later.
}

\section{Between- and Within-Group Changes in Inequality}

We have found no evidence of an increase in overall inequality in Poland in the immediate aftermath of the big bang, regardless of which of several inequality measures we consider. However, this does not mean that there were no winners and losers in the transition.

Figure 4 shows how median income and consumption evolved for four types of households differentiated by main income source of the household head: workers, farmers, mixed worker-farmers, and pensioners. A notable feature of the results is that the use of equivalence scales is important. The per capita household income and consumption plots in the top panel suggest that pensioner-headed households moved from a middle position to being clearly better off 
Figure 3.-Kernel Density Estimates: AdJ. Income

- 1991

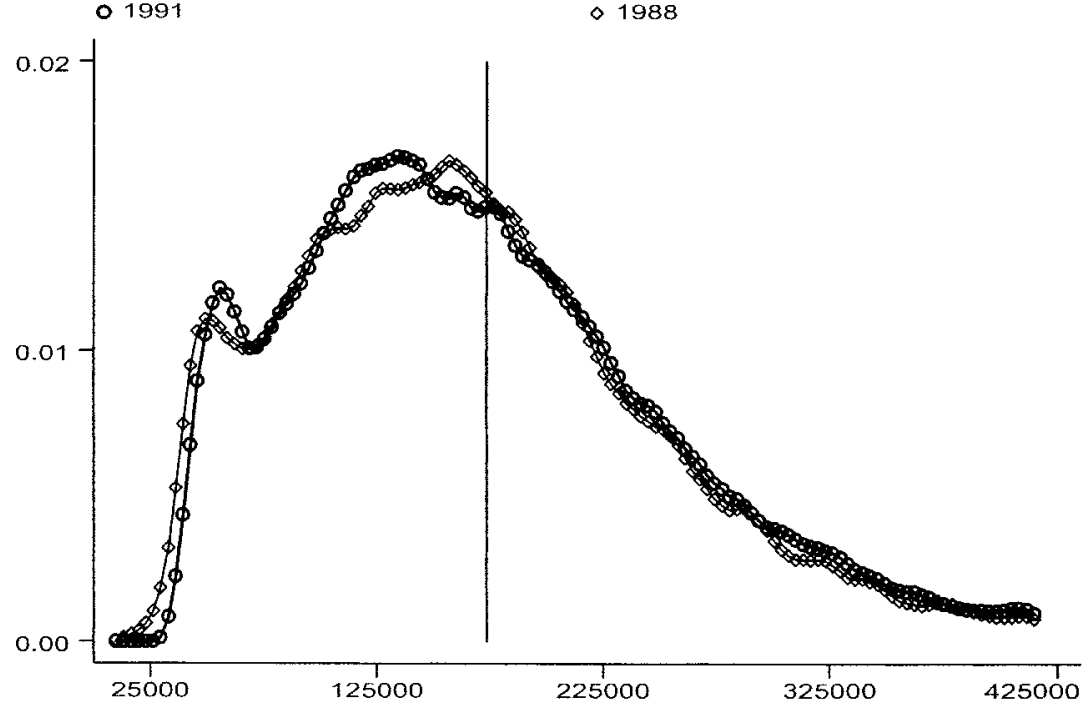

Adjusted Income: 1988,1991

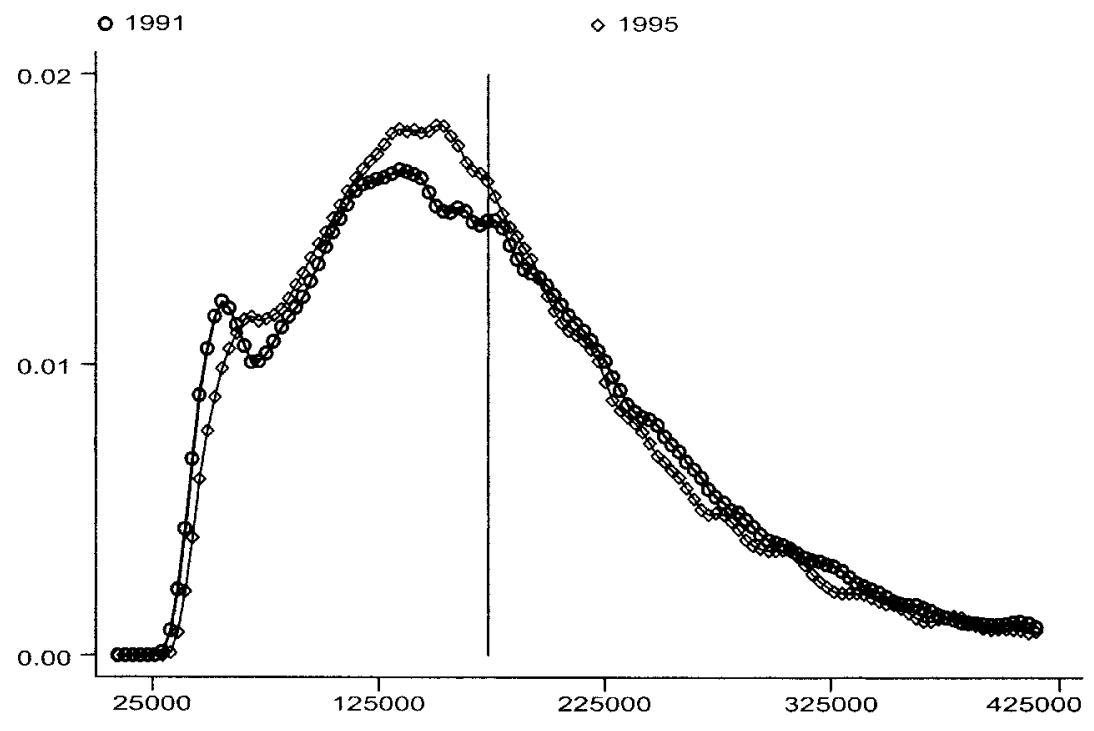

Adjusted Income: 1991,1995

than other households after the big bang. But the per equivalent unit results in the lower panels tell a very different story. ${ }^{14}$ They indicate that pensioner-headed households had much lower median income and consumption than other groups during the 1985-1989 period, and that their relative position improved dramatically after the big bang so as to bring their income and consumption up to almost the same level as the next-lowest group (farmers). As a result, we find that pensions contributed importantly to a

\footnotetext{
${ }^{14}$ The reason for the difference in the scales is that the mean numbers of persons in worker, farmer, worker-farmer, and pensioner households are $3.59,3.64,4.55$, and 1.88 , respectively, whereas the mean numbers of equivalent units are $1.69,1.77,2.08$, and 1.19 , respectively.
}

reduction in inequality. ${ }^{15}$ The main impetus behind the improved relative position of pensioners was a substantial increase in pension levels that took place in 1991. In fact, by 1997, the relative position of pensioner-headed households is inferior only to that of worker-headed households.

We also examined the fractions of households that fall in each quintile of the income distribution, conditional on education or age of the household head (results not shown here). One main finding was the substantial improvement in the relative positions of households whose heads have

15 This is similar to Garner and Terrell's 1998 finding that pensions substantially reduced inequality (as measured by income Gini coefficients) during the early transition years in the Czech and Slovak republics. 
Figure 4.-Median Income, Consumption for Different Socioeconomic Groups
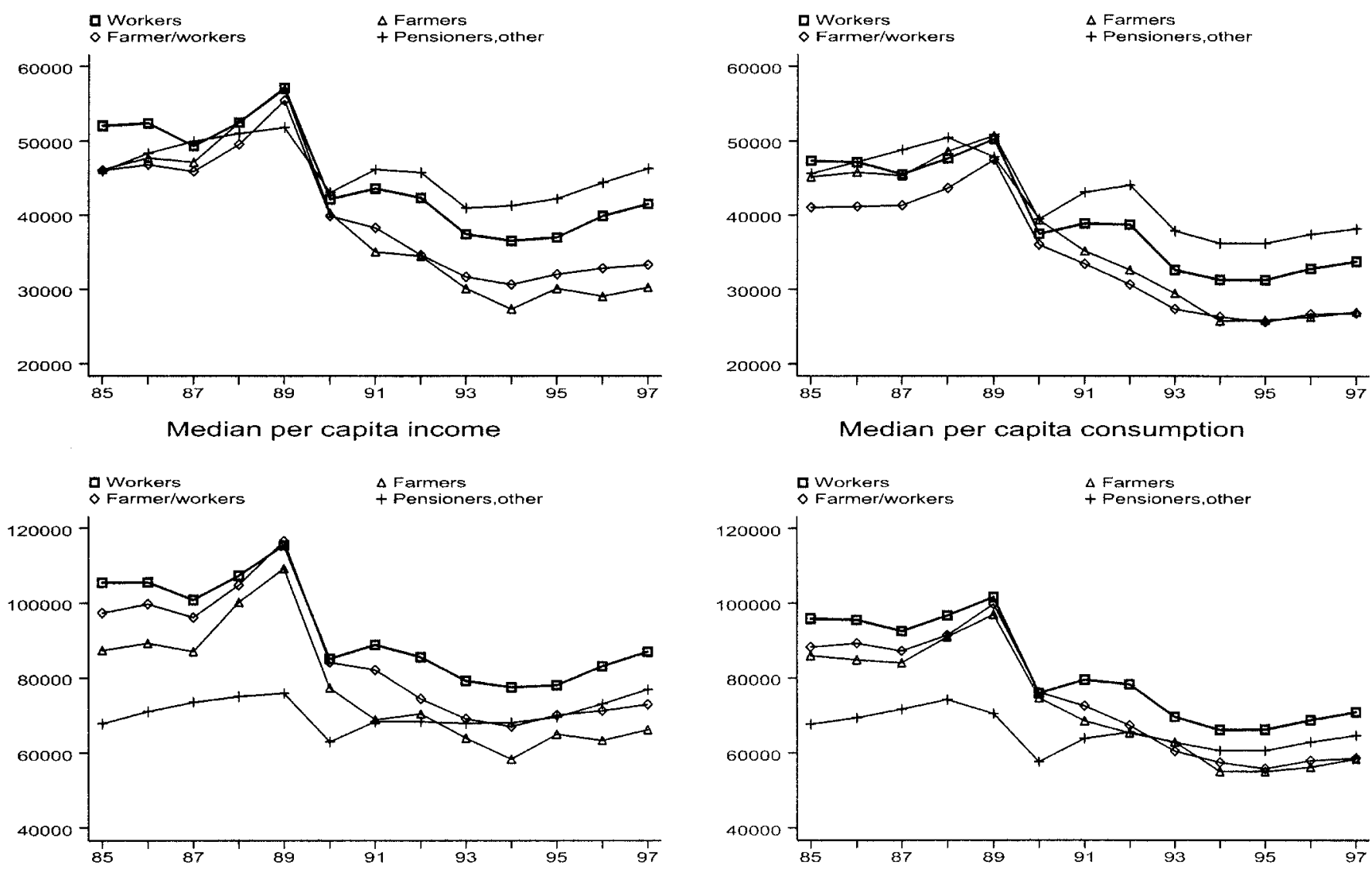

Median income per equivalence scale unit

higher educational qualifications. Another striking result was the improvement of conditions for the old, which resulted from more-generous pensions. Among households in which the head was more than sixty years old, $39.2 \%$ were in the bottom quintile in 1989 , but this dropped to only $24.3 \%$ by 1992 . In contrast, the probabilities that a household with a young (18-30) or middle-aged (31-60) head would fall in the bottom quintile of the income distribution increased over the same period.

Next, we examined the evolution of within-group inequality, which turns out to be very different across different groups. The bottom panel of table 3 shows Gini coefficients estimated separately for each group. These indicate a steady rise in inequality for individuals in worker-headed households, from 0.189 in 1988 to 0.248 in 1997. This increase of 0.059 in the Gini for individuals in these households is almost three times as great as the 0.020 increase in the Gini for the overall income distribution. Within-group inequality actually fell among farmer and mixed worker-farmer households during the transition. There was also a modest increase in inequality within pensioner-headed households.

The most striking result here is the significant and steady increase in inequality among worker-headed households after 1988. The bottom row of table 3 reveals that much of the increase in income inequality among worker-headed

households can be attributed to increased inequality in labor income. When we look at labor income alone, the Gini for this group increased from 0.252 in 1988 to 0.298 in 1997, an increase of 0.046 . Thus, we see that inequality in labor earnings grew substantially more than inequality in the overall income distribution.

\section{E. Earnings Inequality}

To gain more insight into the sources of changes in labor earnings inequality, we also examined the evolution of earnings for individual workers using data available in the HBS. We analyzed changes in the wage structure using OLS and quantile regression techniques. To conserve space, we do not present those results here but only briefly summarize the main findings that are relevant to this paper. (See Keane and Prasad (2002, forthcoming) for detailed results.)

The most prominent result in the wage regressions was the sharp increase in education premia after the transition. Estimates of standard human capital earnings functions indicated that the earnings premium for a college degree relative to a primary school degree increased from $47 \%$ in 1988 to $98 \%$ in 1996 . The high school premium increased from $23 \%$ to $41 \%$ over the same period. Our finding of a sharp increase in education premia after the transition is 
TABle 4.-SOCIAL TRANSFERS

\begin{tabular}{|c|c|c|c|c|c|c|c|c|c|c|}
\hline & 1988 & 1989 & 1990 & 1991 & 1992 & 1993 & 1994 & 1995 & 1996 & 1997 \\
\hline \multicolumn{11}{|l|}{$\begin{array}{l}\text { General Government Expenditures } \\
\text { (in percentage of GDP) }\end{array}$} \\
\hline Cash transfers to individuals & 9.4 & 11.2 & 10.6 & 17.3 & 19.9 & 20.4 & 20.2 & 19.7 & 18.7 & 19.4 \\
\hline Pensions & 7.1 & 8.2 & 8.1 & 12.2 & 14.8 & 15.0 & 14.9 & 14.5 & 14.3 & 14.4 \\
\hline Unemployment benefits & 0.0 & 0.0 & 0.2 & 1.2 & 1.7 & 1.2 & 1.2 & 1.2 & 1.1 & 1.0 \\
\hline Other benefits & 2.3 & 3.0 & 2.3 & 3.9 & 3.4 & 4.2 & 4.1 & 4.0 & 3.3 & 4.0 \\
\hline \multicolumn{11}{|l|}{ Mean Cash Transfers (HBS data) } \\
\hline Total transfers & 41154 & 41792 & 36254 & 44948 & 44694 & 43486 & 44171 & 44860 & 46786 & 48197 \\
\hline (average ratio to total income) & $(23.4)$ & $(21.8)$ & $(26.3)$ & $(32.2)$ & $(33.6)$ & $(31.6)$ & $(32.8)$ & $(32.7)$ & $(32.4)$ & $(31.3)$ \\
\hline Pensions & 29857 & 30497 & 27307 & 33520 & 33346 & 33172 & 34672 & 36240 & 38008 & 40715 \\
\hline (average ratio to total income) & $(17.0)$ & $(15.9)$ & (19.8) & $(24.0)$ & $(25.1)$ & $(24.1)$ & $(25.8)$ & $(26.4)$ & $(26.3)$ & $(26.4)$ \\
\hline Other cash benefits (incl. UI) & 11280 & 11279 & 8927 & 11404 & 11323 & 10315 & 9498 & 8620 & 8777 & 7482 \\
\hline (average ratio to total income) & $(6.4)$ & $(5.9)$ & $(6.5)$ & $(8.2)$ & $(8.5)$ & $(7.5)$ & $(7.1)$ & $(6.3)$ & $(6.1)$ & $(4.9)$ \\
\hline \multicolumn{11}{|l|}{ General Government Balance } \\
\hline (in percentage of GDP) & 0.0 & -7.4 & 3.1 & -6.5 & -6.7 & -2.9 & -3.0 & -3.1 & -3.4 & -3.1 \\
\hline Real GDP (annual \% change) & 4.0 & 0.3 & -11.6 & -7.0 & 2.6 & 3.8 & 5.2 & 7.0 & 6.1 & 6.9 \\
\hline
\end{tabular}

consistent with that of Gorecki (1994), based on his examination of aggregate Polish wage data, and of authors who have examined the wage structure in other transition economies. (See, for example, Ham, Svejnar, and Terrell (1995) for evidence from Czechoslovakia, and Brainerd (1998) for evidence from Russia.)

The other main result in our wage regressions was that experience premia are estimated to have declined sharply in the early years of the transition. These declines were quite large at all quantile points of the distribution that we examined and were especially sharp for older workers. ${ }^{16}$ There was a slight recovery in experience premia in 19941996; this recovery was greater for older workers while, for younger and middle-aged workers, experience premia remain below their pretransition levels even by 1996 .

These results indicate that the returns to general human capital, reflected in education premia, rose markedly after the transition, whereas the returns to experience, especially for older workers, declined sharply in the early years of the transition. This is consistent with the notion of rapid obsolescence of firm- or industry-specific skills during a period of rapid technological change and industrial restructuring (Svejnar, 1996). Workers with higher levels of general human capital are better able to adapt to such changes, but older workers, who typically have higher levels of firm- or industry-specific human capital, face a sharp decline in their earnings potential. This, combined with the increased generosity of pensions, explains the surge in the number of pensioner-headed households in 1991-1992 that we noted in table 1. Indeed, self-selection into retirement probably accounts for the recovery in experience premia for older workers that occurred after 1992 because a large number of older workers, particularly in the 55-65 age bracket, retired in 1991-1992. The patterns of changes in earnings inequality that we have discussed here have important implications

\footnotetext{
${ }^{16}$ Rutkowski (1997) and Lehmann and Wadsworth (2000) report similar findings for Poland and other transition economies.
}

for understanding key aspects of the political economy of the transition process. This is the subject of the next section.

\section{The Targeting of Transfers: A Political Economy Perspective}

The analysis thus far has indicated that, although inequality in labor earnings did increase substantially among workers and worker-headed households, the overall rise in income inequality during the transition was quite effectively dampened by social transfer mechanisms. In this section, we provide a more detailed examination of the targeting of transfers.

We first focus on pensions because they constitute a very important transfer mechanism in Poland. Pension expenditures and the size of the pension rolls increased enormously in the early years of the transition. As shown in table 4, public expenditure figures indicate that total public pension expenditure as a percent of GDP rose from $8 \%$ in 19891990 to almost $15 \%$ by 1992 . The HBS data indicate a similar pattern, with the share of total income accounted for by pensions rising from $16 \%$ in 1989 to $25 \%$ in 1992 . This is particularly interesting given the results from our wage regressions that showed a substantial decline in experience premia for older workers. Our view is that older workers who were adversely affected by the transition were cushioned by increasing the generosity of the pensions. Indeed, the replacement rate (average pension as a ratio of the average wage) rose from about $52 \%$ in $1988-1989$ to $65 \%$ in 1991 and remained above 60\% through 1997 (OECD, 1998).

Furthermore, because older workers had the most to lose from the privatization or closure of existing state-owned firms, giving them the option of moving onto the pension rolls may have been a key factor in removing a potential political obstacle to enterprise restructuring and privatization. This option, reflected in a relaxation of the pension eligibility requirements in 1990-1991, was indeed exercised 
by a large number of workers, resulting in an increase in the number of newly granted pensions from about 0.6 million per year in 1988-1989 to almost 1.4 million in 1991 (OECD, 1998, p. 65). Consistent with this result, we find that, in the HBS data, among households headed by a person in the 55-65 age range, the share of labor income in total income declined from $24 \%$ in 1989 to $12 \%$ by 1994, before recovering somewhat to $16 \%$ by 1997 . In these years, the share of pension income in total income for these households was $64 \%, 74 \%$, and $73 \%$, respectively. ${ }^{17}$

Next, we look at social transfers as a whole. We analyzed the targeting of transfers by comparing shares of income, with and without transfers, going to different quintiles of the respective distributions and also by running nonparametric regressions of transfers on income net of transfers. This analysis revealed that, during the transition, substantial transfers were made to households around and above the median of the distribution. From a static welfare perspective, this suggests that transfers could have been better targeted if the objective was to redistribute income to households near the bottom of the distribution of pretransfer income. However, because individuals in the middle class tend to have a significantly higher propensity to vote than do individuals at lower income levels, transfers targeted in this manner may have been more effective at "buying" the social stability that characterized the transition period, notwithstanding the potentially disruptive effects of the economic transformation. (See Roland (1997) for a related analysis.)

Thus, transfers may have contributed not only to social stability but also to ensuring the conditions necessary for reforms such as privatization and enterprise restructuring that paved the way for high growth. As shown in table 4, this resulted in a substantial increase in the general government budget deficit in the early years of the transition. Although there was an attempt to hold the line on transfers in 1990, the increased generosity of pensions and other social benefits led to a mushrooming of the deficit in 1991-1992. This proved unsustainable, and, by 1993, growth in transfer expenditures (as a percentage of GDP) had been halted, although pensions and other social benefits were at a higher level than in the pretransition years. The increase in aggregate inequality after 1993 is yet another indicator of how important the growth in transfers was in dampening the rise in overall inequality in the early years of the transition.

To summarize, the analysis in this paper highlights the role of policy choices, as embodied in transfer and other policies, on the dynamics of inequality during the transition to a market economy. In particular, we have argued that the increase in transfer expenditures during the critical early

\footnotetext{
${ }^{17}$ Among households with heads in the 45-55 age range and in lower age ranges, there was a small drop from 1989 to 1992 in the share of income from labor income, but this was mostly offset by an increase in other social benefits rather than pensions. Among households with heads aged 65 and older, pensions constitute $85 \%-90 \%$ of total income, with labor income accounting for barely $2 \%$.
}

years of the transition may have played an important role in setting the stage for the successful economic transition in Poland.

\section{Inequality, Transfers, and Growth: Some Cross-Country Evidence}

Our detailed analysis of the Polish transition experience has suggested that, from a political economy perspective, the use of transfer mechanisms to mitigate the potential rise in inequality during the transition to a market economy may have important implications for the success of the transition process. In this section, we expand our analysis to provide a cross-country perspective on the experiences of the transition economies of Eastern Europe in terms of inequality, social transfers, and growth.

A prerequisite for the investigation is that we have available for each country two measures of income inequality: one for a year prior to the start of the transition and a second for a year several years after the start of the transition (so that the data do not simply capture the effects of the initial phase of transition on inequality). It is also important that the pre- and posttransition Gini values for each country be based on similar measures of income, similar sampling time frames, similar data sets, and so on so that the measures are reasonably comparable. Table 5 reports pre- and posttransition Gini values, obtained from six different sources that we believe reasonably satisfy these comparability criteria. The sources are Milanovic (1998, 1999), World Bank (1997, 1999, 2000), and OECD (1997).

The Gini coefficients in table 5 are all for the respective individual income distributions, assigning to each individual the per capita income of the household. ${ }^{18}$ We have argued earlier that it would be more reasonable to use equivalence scales to accommodate household economies of scale. But only per capita income Ginis are available for most transition economies. Ginis based on labor earnings are available for more countries, but these would not account for the effect of transfers on the distribution of total income, which is our focus. Some omissions from the table are noteworthy. We require that posttransition Gini values be in the 1995-1997 period. As a result, we could not obtain posttransition values for the Slovak Republic, Uzbekistan, Turkmenistan, and Moldova. Gini values for these countries are constructed by Milanovic (1998) for 1993, but this is too soon after the start of the transition for our purposes.

Table 5 reports annualized cumulative GDP growth in the first eight years of transition. This corresponds to the 1990-

\footnotetext{
18 There were five cases in which we had Ginis for both 1988 and 1989 and two cases (besides Poland) in which we had Ginis for both 1995 and 1996. In the former cases, we took 1988 (the earlier year), and in the latter cases we took 1996 (the later year). Also note that the posttransition Gini values for Lithuania and Kazakhstan are for consumption rather than income. This probably understates the increase in income inequality in these countries. Because these countries also had poor growth performance, the effect is, if anything, to understate the negative correlation between GDP growth and changes in inequality that we find later.
} 
TABLE 5.-CROSS-COUNTRY DATA

\begin{tabular}{|c|c|c|c|c|c|c|c|}
\hline \multirow[b]{2}{*}{ Country } & \multirow{2}{*}{$\begin{array}{l}\text { Annualized } \\
\text { Cumulative } \\
\text { GDP Growth }\end{array}$} & \multicolumn{3}{|c|}{ Gini Coefficients } & \multirow{2}{*}{$\begin{array}{c}\text { Average Cash } \\
\text { Transfers ( } \% \\
\text { of GDP) }\end{array}$} & \multirow{2}{*}{$\begin{array}{l}\text { Transition } \\
\text { Indicators }\end{array}$} & \multirow{2}{*}{$\begin{array}{c}\text { Initial } \\
\text { Condition } \\
\text { Indicator }\end{array}$} \\
\hline & & Pretransition & Posttransition & Difference & & & \\
\hline Poland & 1.25 & 0.272 & 0.301 & 0.029 & 17.7 & 14.3 & 1.18 \\
\hline Slovenia & 0.47 & 0.174 & 0.223 & 0.049 & 14.8 & 13.0 & 1.24 \\
\hline Czech Republic & -0.29 & 0.194 & 0.254 & 0.060 & 12.1 & 14.7 & 1.43 \\
\hline Hungary & -1.15 & 0.248 & 0.308 & 0.060 & 16.5 & 14.7 & 1.47 \\
\hline Romania & -2.18 & 0.233 & 0.280 & 0.047 & 8.9 & 9.8 & 0.94 \\
\hline Estonia & -3.05 & 0.230 & 0.354 & 0.124 & 10.0 & 12.5 & -0.33 \\
\hline Belarus & -4.23 & 0.228 & 0.288 & 0.060 & 8.9 & 8.3 & -1.19 \\
\hline Kazakhstan & -5.03 & 0.257 & 0.354 & 0.097 & 6.9 & 8.3 & -1.07 \\
\hline Bulgaria & -5.03 & 0.228 & 0.317 & 0.089 & 11.8 & 10.3 & 0.55 \\
\hline Lithuania & -5.65 & 0.225 & 0.324 & 0.099 & 9.6 & 10.5 & -0.52 \\
\hline Russia & -6.14 & 0.238 & 0.380 & 0.142 & 7.5 & 9.7 & -0.34 \\
\hline Kyrgyzstan & -6.67 & 0.260 & 0.405 & 0.145 & 12.4 & 10.3 & -1.03 \\
\hline Latvia & -6.89 & 0.225 & 0.320 & 0.095 & 11.8 & 10.2 & -0.46 \\
\hline Ukraine & -10.64 & 0.233 & 0.473 & 0.240 & 9.4 & 8.7 & -0.91 \\
\hline
\end{tabular}

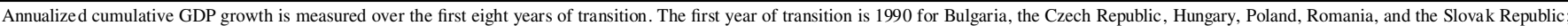

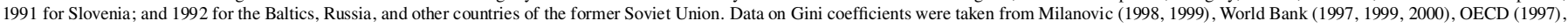

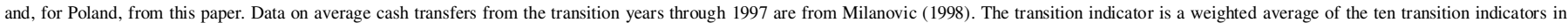

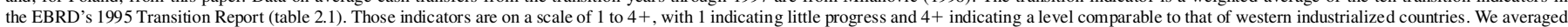

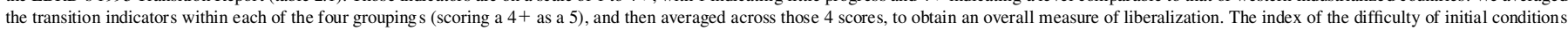
(a higher score indicates more-favorable conditions) is taken from de Melo et al. (1997).

1997 period for all Eastern European countries except Romania, 1991-1998 for Romania, and 1992-1999 for Russia and the other former Soviet Union countries. The table also reports the mean level of social (cash) transfers, as a percentage of GDP, from the first year of the transition through 1997. Note that Poland and Slovenia are the only countries that surpassed pretransition levels of GDP after eight years. These countries also have among the highest average levels of social transfers $(17.7 \%$ of GDP for Poland and $14.8 \%$ for Slovenia).

Finally, table 5 also reports two variables that could be relevant for explaining the different growth experiences of the transition economies. The first is a summary measure of the EBRD transition indicators for each country, taken from the EBRD's 1995 Transition Report. This is a measure of government policies in terms of the degree of transition towards a market economy framework. ${ }^{19}$ The second variable is a measure of the initial conditions facing each country at the start of the transition. This variable, taken from de Melo, Denizer, Gelb, and Tenev (1997, henceforth MDGT), is constructed using factor analysis and is based on the degree of industrialization, extent of initial macroeconomic imbalances, geographic orientation of trade, and length of time under communism. We report the first com-

\footnotetext{
${ }^{19}$ The EBRD report contains ten measures of the degree of transition to a market economy. Three of the measures relate to enterprises: the degree of large and small scale enterprise privatization, and the degree of enterprise restructuring (including elimination of soft-budget constraints). Three measures relate to markets and trade: the degree of price liberalization, the degree of trade liberalization and access to foreign exchange, and the extent of enforcement actions to prevent abuse of market power. Two measures relate to financial institutions (banking reform and interest rate liberalization, and the establishment of securities markets), and two measures capture the extent and effectivenes s of the legal framework for securing property rights and regulating business activity.
}

mon factor from their analysis, with a higher score indicating more-favorable initial conditions. ${ }^{20}$

Figure 5 plots cumulative GDP growth in the first eight years of transition against the change in the Gini coefficient. A strong negative relationship is obvious, with those countries that have experienced better growth performance also having smaller increases in income inequality. The simple correlation is -0.86 . Figure 5 also plots growth against the ratio of government transfers to GDP for all eighteen countries for which we were able to obtain transfer data. The relationship is strongly positive, with a simple correlation of 0.67 (0.61 in the subsample of fourteen countries for which we have Gini coefficients). Finding a positive correlation between transfers and growth is particularly surprising given the blatant denominator bias driving the correlation in the opposite direction (higher output growth increases the denominator of the transfer to GDP ratio). ${ }^{21}$ It is interesting that both of these results have also been reported by authors such as Perotti (1996) for a different but much larger sample of industrial and developing countries.

These results are at least not inconsistent with recent developments in growth theory that imply that redistribution to enhance equality may actually enhance rather than dampen growth. They also echo Perotti's 1996 more general finding that redistributive expenditures are positively asso-

\footnotetext{
${ }^{20}$ It is worth noting that this measure is very highly correlated with distance from Western Europe. Thus, by using this variable to explain growth, one risks falling into the vacuous conclusion that the central Asian countries did poorly because they are central Asian countries. However, it is interesting that Uzbekistan did much better (relatively) than would be expected given its initial conditions, whereas Bulgaria and Latvia did much worse.

${ }^{21}$ Another problem is that higher transfers do not necessarily imply more redistribution. As noted by Commander and Lee (1998), transfers in Russia have actually become regressive in the transition.
} 
Figure 5.-Transfers, Inequality, and Growth During Transition
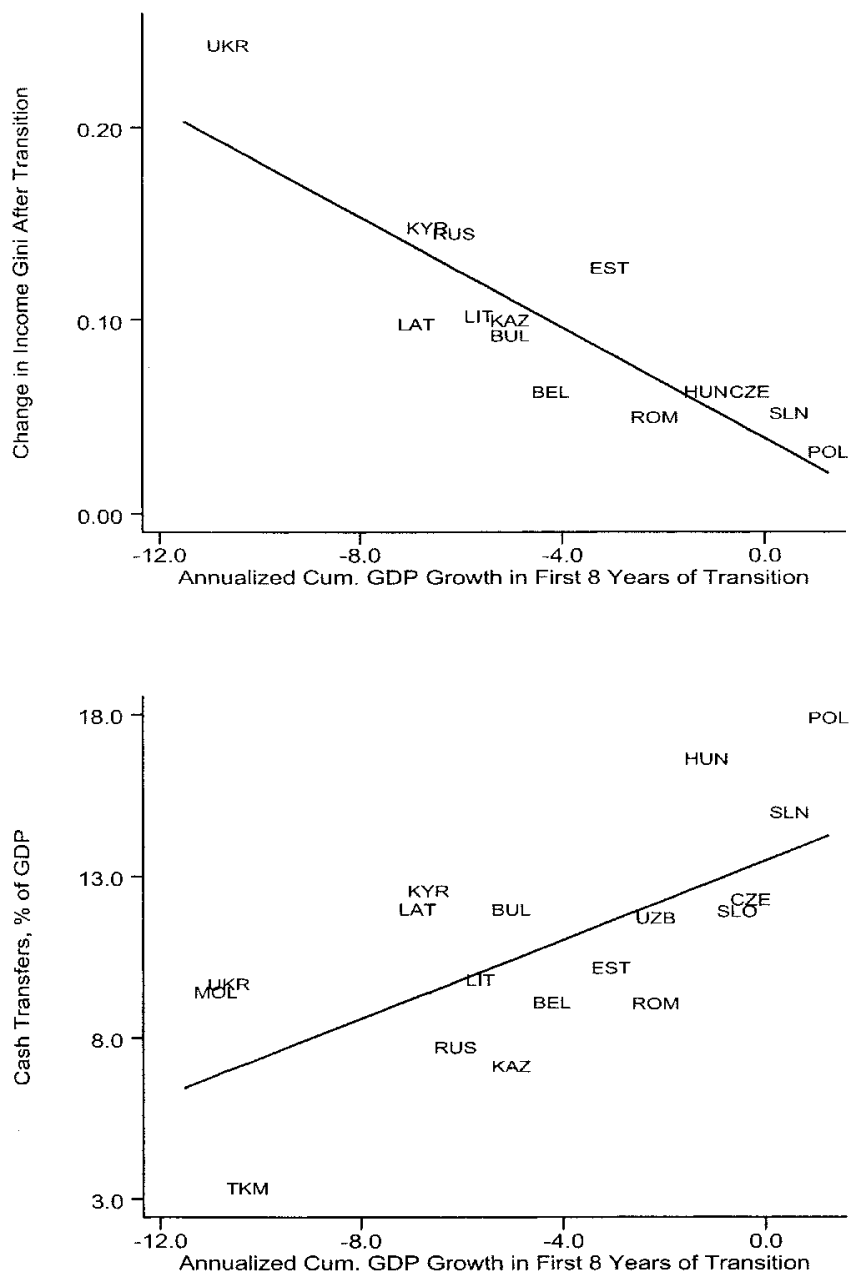

ciated with growth. But it is of course possible that some third factor explains both good growth performance and the maintenance of income equality in transition economies, and that the correlation between growth and the change in inequality has no causal interpretation. To investigate further, we tried regressions of growth on changes in the Gini coefficients, along with the EBRD measure of the extent of liberalization and the MDGT measure of initial conditions facing each country (the idea being that the extent of liberalization or the difficulty of initial conditions are plausible omitted factors that could explain both growth and changes in inequality).

These results, reported in table 6 indicate that, individually, the EBRD transition indicator, the MDGT initial conditions measure, and the changes in the Gini coefficients are all highly significantly related to GDP growth. In column 4, we include all three variables. Interestingly, only the EBRD transition indicator and the Gini difference are significant, whereas the initial-condition indicator is not. This suggests that initial conditions did not matter for growth once subsequent policy choices are controlled for. The results in column 5 confirm this because the adjusted $R^{2}$ increases when the initial condition indicator is excluded from the regression. The coefficient estimates imply that marketoriented liberalization is positively associated with growth, and that increasing inequality is negatively associated with growth. ${ }^{22}$

Of course, a problem with these results is the potential endogeneity of the change in inequality. In an attempt to address this problem, in column 6 we instrument for the Gini difference using the initial-condition indicator. This procedure relies on the (admittedly strong) identifying assumption that initial conditions do not directly affect growth once we control for subsequent policy choices (the transition indicator). Granted that, in column 6 we are identifying the effect of inequality on growth through variation in inequality outcomes that can be attributed to initialconditions differences (as opposed to changes in inequality that may have been caused by subsequent growth outcomes). Interestingly, the coefficient on the Gini difference does not change much and remains highly significant. In fact, this coefficient is quite stable whether we include initial conditions in the regression (column 4), use initial conditions to instrument for the difference (column 6), or exclude initial conditions entirely and run OLS (column 5).

A coherent interpretation of these results would be that greater progress towards a market economy framework enhances growth but that, conditional on the degree of liberalization, policy that maintains a greater degree of equality is more conducive to growth. Initial conditions do not affect growth directly once one controls for policy choices, but initial conditions do seem to matter through their effects on policy. In particular, countries with better initial conditions have not only made more-rapid progress towards liberalization, but they have also tended to pursue policies that have resulted in smaller increases in inequality in the process. Only to the extent that better initial conditions have led to more liberalization or more equality have they enhanced growth. Of course, as noted, this interpretation relies on a strong identifying assumption, and other interpretations cannot be ruled out.

We are naturally cautious about drawing strong conclusions from fourteen data points. But, on the other hand, note that this is not really a "small sample" but rather the entire population of Eastern European countries experiencing the transition process (barring a few for which data are not available). One might feel we could obtain more-conclusive results by exploiting the panel aspect of the data, but inspection of the data over time reveals that, for each country, there is tremendous persistence in growth performance, as well as in the degree of liberalization and the extent of increase in income inequality. That is, those

\footnotetext{
${ }^{22}$ As additional robustnes s tests, we also tried including as regressors the initial level of inequality and a dummy for countries of the former Soviet Union and an interaction of this dummy with the change in inequality. These additional controls had little effect on the OLS results presented in table 6 .
} 
TABLE 6.-CRoss-Country RegRessions

\begin{tabular}{|c|c|c|c|c|c|c|}
\hline & (1) & (2) & (3) & (4) & (5) & (6) \\
\hline Change in Gini*100 & $\begin{array}{l}-0.520 * \\
(0.089)\end{array}$ & & . . & $\begin{array}{l}-0.365^{*} \\
(0.075)\end{array}$ & $\begin{array}{l}-0.381 * \\
(0.065)\end{array}$ & $\begin{array}{l}-0.442 * \\
(0.149)\end{array}$ \\
\hline Transition indicator & $\ldots$ & $\begin{array}{l}1.121^{*} \\
(0.261)\end{array}$ & $\ldots$ & $\begin{array}{l}0.587^{*} \\
(0.243)\end{array}$ & $\begin{array}{l}0.671^{*} \\
(0.154)\end{array}$ & $\begin{array}{l}0.599 * \\
(0.225)\end{array}$ \\
\hline Initial conditions index & $\ldots$ & $\ldots$ & $\begin{array}{l}2.617 * \\
(0.562)\end{array}$ & $\begin{array}{l}0.283 \\
(0.616)\end{array}$ & $\ldots$ & $\ldots$ \\
\hline Constant & $\begin{array}{l}1.020 \\
(0.967)\end{array}$ & $\begin{array}{l}-16.388^{*} \\
(2.952)\end{array}$ & $\begin{array}{l}-4.124^{*} \\
(0.551)\end{array}$ & $\begin{array}{l}-6.990 * \\
(2.751)\end{array}$ & $\begin{array}{l}-7.757^{*} \\
(2.107)\end{array}$ & $\begin{array}{l}-6.373 \\
(3.731)\end{array}$ \\
\hline Adjusted $R^{2}$ & 0.72 & 0.57 & 0.61 & 0.83 & 0.89 & 0.88 \\
\hline Number of observations & 14 & 14 & 14 & 14 & 14 & 14 \\
\hline
\end{tabular}

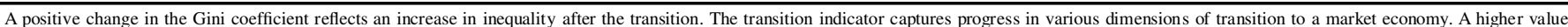

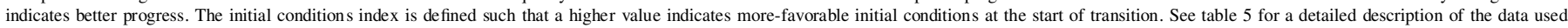

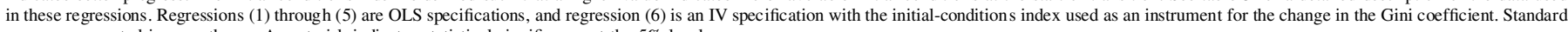
errors are reported in parentheses. An asterisk indicates statistical significance at the $5 \%$ level.

countries that have relatively good growth performance, a relatively high degree of liberalization, and a relatively low increase in inequality tend to remain that way throughout the transition, and vice versa. Thus, we do not feel that there is much to be gained by looking at these data as a panel. It would be an illusion to think there are many more than fourteen independent observations to work with here.

Our overall interpretation of these results is that, consistent with the Polish experience that we have analyzed in detail in this paper, the use of social transfer mechanisms and other policies to buffer the potential increase in income inequality, especially in the critical early phase of transition, appears to be important in generating a successful transition to a market economy. We have argued that the Polish experience points to an interesting example of targeting of transfers that may have been crucial for garnering political support for the drastic market-oriented reforms that facilitated Poland's strong growth performance in the 1990s.

\section{Concluding Remarks}

This paper has argued, based on detailed analysis of household income and consumption data for the period 1985-1997, that in Poland there is little evidence of a substantial increase in overall inequality during the transition that began in 1989-1990. This contradicts the conventional wisdom that the process of transition to a market economy is inevitably accompanied by a surge in inequality. However, we did find that earnings inequality among workers increased substantially during the transition. We also documented that social transfer mechanisms played an important role in dampening the increase in overall inequality and in between-group income dynamics. We argued that, although the structure of transfers may not necessarily have been ideal from the perspective of preventing an increase in poverty, transfer mechanisms may have played a critical role in maintaining social stability and in reducing political resistance to the structural reforms that were undertaken in the early years of the transition and that facilitated Poland's subsequent strong growth performance. Finally, we presented cross-country evidence on inequality, transfers, and growth in transition economies that, although not conclusive, is consistent with the notion that social transfers and other policies aimed at mitigating increases in inequality (especially in the critical early phase of transition) may be conducive to growth.

\section{REFERENCES}

Aghion, Philippe, and Simon Commander, "On the Dynamics of Inequality in the Transition," Economics of Transition 7:2 (1999), 275298.

Aghion, Philippe, and Patrick Bolton, "A Trickle-Down Theory of Growth and Development with Debt Overhang," Review of Economic Studies 64:2 (1997), 151-162.

Aghion, Philippe, Eva Caroli, and Cecilia García-Peñalosa, "Inequality and Economic Growth: The Perspective of the New Growth Theories," Journal of Economic Perspectives 37 (1999), 1615-1660.

Alesina, Alberto, and Dani Rodrik, "Distributive Politics and Economic Growth," Quarterly Journal of Economics 109:2 (1994), 465-490.

Atkinson, Anthony B., "On the Measurement of Inequality," Journal of Economic Theory 2:3 (1970), 244-263.

Atkinson, Anthony B., Lee Rainwater, and Timothy M. Smeeding, "Income Distribution in OECD Countries: Evidence from the Luxembourg Income Study," OECD Social Policy Studies no. 18 (Paris: OECD, 1995).

Banerjee, Abhijit, and Andrew F. Newman, "Occupational Choice and the Process of Development," Journal of Political Economy 101:2 (1993), 274-298.

Banerjee, Abhijit, and Esther Duflo, "Inequality and Growth: What Can the Data Say?" NBER working paper no. 7793 (2000).

Benabou, Roland, "Inequality and Growth," NBER Macroeconomics Annual 11 (1996), 11-74.

Brainerd, Elizabeth, "Winners and Losers in Russia's Economic Transition," American Economic Review 88:5 (1998), 1094-1116.

Commander, Simon, and Une Lee, "How Does Public Policy Affect the Income Distribution? Evidence from Russia, 1992-1996," EBRD manuscript (1998).

De Melo, Martha, Cevdet Denizer, Alan Gelb, and Stoyan Tenev, "Circumstance and Choice: The Role of Initial Conditions and Policies in Transition Economies," World Bank Policy Research working paper no. 1866 (Washington, DC: World Bank, 1997).

Dewatripont, Mathias, and Gérard Roland, "Transition as a Process of Large-Scale Institutional Change," Economics of Transition 4:1 (1996), 1-30.

Engel, E., "Die Lebenskosten belgischer Arbeiter-Familien früher und jetzt," Bulletin de l'Institut International de Statistique 9 (1895), $1-129$.

European Bank for Reconstruction and Development, Transition Report 2000 (London: EBRD, 2000).

Evans, David S., and Boyan Jovanovic, "An Estimated Model of Entrepreneurial Choice under Liquidity Constraints," Journal of Political Economy 97:4 (1989), 808-827. 
Forbes, Kristin, "A Reassessment of the Relationship Between Inequality and Growth," American Economic Review 90 (2000), 869-887.

Galor, Oded, and Joseph Zeira, "Income Distribution and Macroeconomics," Review of Economic Studies 60:1 (1993), 35-52.

Garner, Thesia, and Katherine Terrell, "A Gini Decomposition of Inequality in the Czech and Slovak Republics During the Transition," Economics of Transition 6:1 (1998), 23-46.

Gomułka, Stanisław, "The Polish Model of Transformation and Growth," Economics of Transition 6:1 (1998), 163-171.

Gorecki, Brunon, "Evidence of a New Shape of Income Distribution in Poland," Eastern European Economics 32:3 (1994), 32-51.

Gottschalk, Peter, and Timothy M. Smeeding, "Cross-National Comparisons of Earnings and Income Inequality," Journal of Economic Literature 35:2 (1997), 633-687.

Ham, John C., Jan Svejnar, and Katherine Terrell, "Czech Republic and Slovakia" (pp. 91-146) in Simon Commander and Fabrizio Coricelli (Eds.), Unemployment, Restructuring and the Labor Market in Eastern Europe and Russia (Washington, DC: World Bank, 1995).

IMF, "Poland: The Path to a Market Economy," occasional paper no. 113 (Washington, DC: IMF, 1994).

Keane, Michael P., and Eswar S. Prasad, "Consumption and Income Inequality During the Transition to a Market Economy: Poland 1985-92," IMF Staff Papers 47 (November 1991, Special Issue), $121-154$.

_ "Changes in the Structure of Earnings During a Period of Rapid Technological and Institutional Change: Evidence from the Polish Transition," IMF working paper (Washington, DC: IMF, 2002, forthcoming).

Kuznets, Simon, "Economic Growth and Income Inequality," American Economic Review 45 (1955), 1-28.

Lehmann, Hartmut, and Jonathan Wadsworth, "Tenures that Shook the World: Worker Turnover in Russia, Poland, and Britain," Journal of Comparative Economics 28:4 (2000), 639-664.

McClements, Leslie, "Equivalence Scales for Children," Journal of Public Economics 8:2 (1977), 191-210.

Milanovic, Branko, "Income, Inequality and Poverty During the Transition from Planned to Market Economy," World Bank Regional and Sectoral Studies (Washington, DC: World Bank, 1998).

"Explaining the Increase in Inequality During Transition," Economics of Transition 7:2 (1999), 299-341.

OECD, "OECD Economic Surveys: Poland" (Paris: OECD, 1997, 1998).

Perotti, Roberto, "Growth, Income Distribution and Democracy: What the Data Say," Journal of Economic Growth 1:2 (1996), 149-187.

Persson, Torsten, and Guido Tabellini, "Is Inequality Harmful for Growth?" American Economic Review 84:3 (1994), 600-621.

Roland, Gérard, "Political Constraints and the Transition Experience" (pp. 169-188) in Salvatore Zecchini (Ed.), Lessons from the Economic Transition: Central and Eastern Europe in the 1990s (Amsterdam: Kluwer Academic Publishers, 1997).

Rutkowski, Jan, "Low Wage Employment in Transitional Economies of Central and Eastern Europe," MOCT-MOST: Economic Policy in Transitional Economies 7 (1997), 105-130.

Shorrocks, Anthony F., "Inequality Decomposition by Population Subgroups," Econometrica 52:6 (1984), 1369-1385.

Svejnar, Jan, "Enterprises and Workers in the Transition: Econometric Evidence," American Economic Review Papers and Proceedings $86: 2$ (1996), 123-127.

Torrey, Barbara Boyle, Timothy M. Smeeding, and Debra Bailey, "Income Transition s in Central European Households," Economic Development and Cultural Change 47:2 (1999), 237-257.

World Bank, "Understanding Poverty in Poland," Country Study (Washington, DC: World Bank, 1995).

"World Development Indicator s" (Washington, DC: World Bank, 1997-2000).

\section{APPENDIX ACCOUNTING FOR THE CHANGE IN SURVEY FREQUENCY IN 1993}

A few important changes were introduced to the HBS in 1993. Starting in that year, household s were surveyed for only one month rather than for a full quarter. In addition, the sampling scheme was modified to provide better coverage of the self-employed and other groups such as police, security, and military personnel. Other aspects of the survey, such as the two-stage sampling scheme and the structure of the survey instrument, were left essentially unchanged.

For the purposes of measuring cross-sectiona 1 inequality, the change in survey frequency is the most important change. In this appendix, we develop a technique for adjusting the 1993-1997 income and consumption data for the increased variability that may be attributable to the shift from quarterly to monthly reporting. A more detailed description, along with relevant estimation results, can be found in the working paper version of this paper.

We begin by assuming the following "statistical" or "forecasting" model for income:

$$
Y_{h t}=\alpha_{1 t}+\beta_{t} X_{h t}+\sigma_{t} \epsilon_{h t},
$$

where $Y_{h t}$ is income of household $h$ in period $t, X_{h t}$ is a vector of household characteristic s used to predict household income, and $\epsilon_{h t}$ is the unpredictable or idiosyncratic component of household income scaled to have a standard deviation of unity. The time-specific standard deviation that scales this idiosyncratic component is denoted by $\sigma_{t}$. Our objective is to estimate the increase in $\sigma_{t}$ during 1993-1997 that is due solely to the switch to a monthly reporting interval.

We estimate equation (1) separately for each quarter from 1985-1992 and for each month from 1993-1997. The variables included in $X_{h t}$ are controls for education level, age and sex of the household head, controls for presence of a spouse and age of the spouse, and controls for household size, urban residence, and primary income source of the household head. Although most of the coefficients were stable over time in these regres-

Figure A1.-Time Polynomials, Stage II Regressions

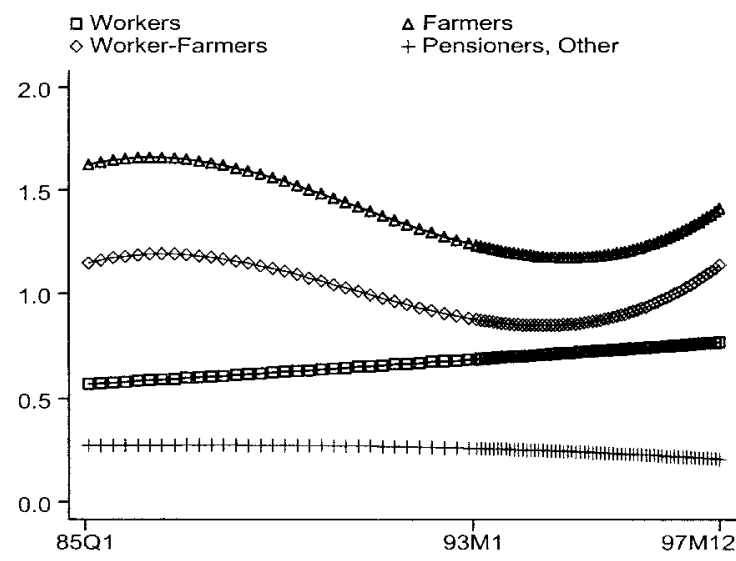

Fitted Time Polynomials

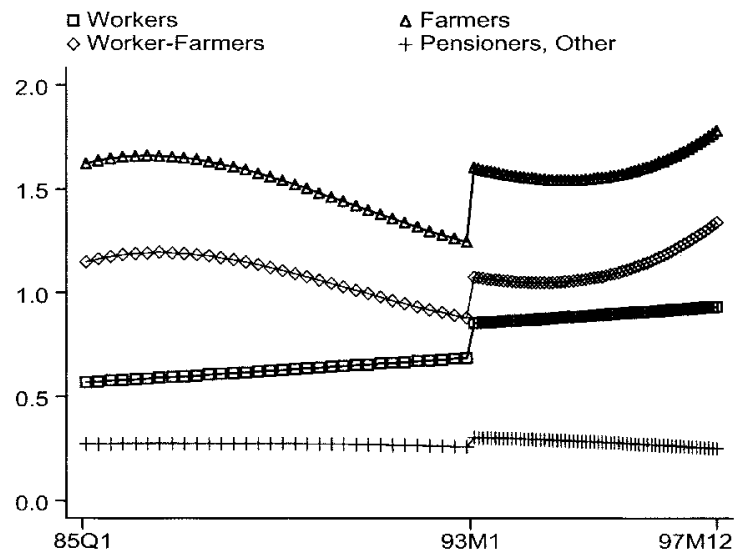

Fitted Time Polynomials + Estimated Dummy for 93-97 
Table A1.-Equivalence Scales as a Function of Household Composition

\begin{tabular}{|c|c|c|c|c|c|}
\hline \multirow[b]{2}{*}{ Household Type: } & \multirow[b]{2}{*}{ GUS } & \multirow[b]{2}{*}{ OECD } & \multirow[b]{2}{*}{ McClements } & \multicolumn{2}{|c|}{ Food-Share Equations } \\
\hline & & & & OLS & IV \\
\hline \multicolumn{6}{|l|}{ Single-person households } \\
\hline $1 \mathrm{HD}=$ Male, $31-60$ & 0.54 & 0.59 & 0.55 & 0.74 & 0.71 \\
\hline $2 \mathrm{HD}=$ Male, $18-30$ & 0.54 & 0.59 & 0.55 & 0.72 & 0.70 \\
\hline $3 \mathrm{HD}=$ Male, $>60$ & 0.54 & 0.59 & 0.55 & 0.74 & 0.68 \\
\hline $4 \mathrm{HD}=$ Female, $31-60$ & 0.46 & 0.59 & 0.55 & 0.66 & 0.65 \\
\hline $5 \mathrm{HD}=$ Female, $18-30$ & 0.46 & 0.59 & 0.55 & 0.63 & 0.64 \\
\hline $6 \mathrm{HD}=$ Female,$>60$ & 0.46 & 0.59 & 0.55 & 0.60 & 0.53 \\
\hline \multicolumn{6}{|l|}{ Married Couples } \\
\hline $7 \mathrm{HD}=$ Male, 31-60; Female, 31-60 & 1.00 & 1.00 & 1.00 & 1.00 & 1.00 \\
\hline $8 \mathrm{HD}=$ Male, $18-30 ;$ Female $18-30$ & 1.00 & 1.00 & 1.00 & 0.91 & 0.92 \\
\hline $9 \mathrm{HD}=$ Male, $>60 ;$ Female $>60$ & 1.00 & 1.00 & 1.00 & 1.03 & 0.92 \\
\hline \multicolumn{6}{|l|}{ Married couples with one child } \\
\hline \multicolumn{6}{|l|}{$\mathrm{HD}=$ Male, 31-60; Female, 31-60 } \\
\hline 10 Male/Female, $<7$ & 1.23 & 1.29 & 1.17 & 1.12 & 1.10 \\
\hline 11 Male/Female, 8-12 & 1.32 & 1.29 & 1.24 & 1.16 & 1.14 \\
\hline 12 Male, $13-17$ & 1.46 & 1.29 & 1.29 & 1.19 & 1.17 \\
\hline 13 Female, 13-17 & 1.41 & 1.29 & 1.29 & 1.14 & 1.13 \\
\hline \multicolumn{6}{|l|}{ Married Couples with older dependents } \\
\hline \multicolumn{6}{|l|}{ HD $=$ Male, 31-60; Female, 31-60 } \\
\hline 14 Male, $>60$ & 1.54 & 1.41 & 1.40 & 1.24 & 1.23 \\
\hline 15 Female, $>60$ & 1.46 & 1.41 & 1.40 & 1.32 & 1.29 \\
\hline 16 Male, $>60 ;$ Female, $>60$ & 2.00 & 2.00 & 1.80 & 1.63 & 1.59 \\
\hline
\end{tabular}

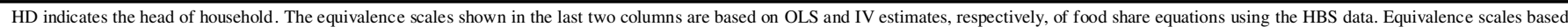
on IV estimates (column 5) are used in the paper.

sions, one interesting aspect was that the education level of the household head became more important as the transition progressed. A key feature of the results was that the $R^{2}$ values dropped sharply after 1993. This is presumably due to greater idiosyncratic variability of income, as well as greater relative importance of measurement error, when income is reported at a monthly rather than quarterly frequency.

Next, we assume that the standard deviations of the residuals from estimation of equation (1) follow the process:

$$
\begin{gathered}
\ln \sigma_{t}=\pi_{0}+\pi_{1} t+\pi_{2} t^{2}+\pi_{3} t^{3}+\pi_{4} Y B_{t}+\pi_{5} I[t>96]+\eta_{t} \\
t=2,4, \ldots, 95 ; t=97,98, \ldots, 156 .
\end{gathered}
$$

Here $t$ is a monthly time index. For the years 1985 through 1992, the data are quarterly, so $t$ is assigned as the midpoint of the interval covered by each quarter (that is, $t=2,4, \ldots, 95$ ). The variable $I[t>96]$ is an indicator for the period 1993-1997. Thus, the coefficient $\pi_{5}$ captures the structural shift in the error standard deviation attributable to the shift in data frequency. The time polynomials capture the evolution of the error standard deviation over time due to changes in within-group income inequality, controlling for the group characteristic s included in $X_{h t}$. The term $Y B_{t}$ controls for the effect of changes in mean income on the error standard deviation. Finally, $\eta_{t}$ capture s purely idiosyncratic periodspecific changes in income variability.

Analysis of the residuals from equation (1) indicates that households with different primary income sources (that is, worker-heade $\mathrm{d}$ households , farm households, mixed farmer-worker households, and pensioner households ) have very different error variances, as well as different behavior of the error variances over time. Therefore, we estimate equation (2) separately for each household type, using the time series of residual variances from (1).

In figure A1 (top panel), we plot the time polynomial, holding $Y B_{t}$ fixed at the full sample mean, and setting $I[t>96]$ to zero. These plots indicate that within-group income inequality did begin to grow substantially in 1996-1997, even after controlling for changes in the scale of real income. Including the time dummy (lower panel) shows the effect of the adjustment on within-group residual variances. It is interesting to note that residual inequality trends up over the entire sample for worker-headed households, is rather flat for pensioner-heade d households, and, for the other two groups, declines through the early 1990s and then begins to increase.

Finally, we adjust the income data for 1993-1997 to account for the increase in the idiosyncratic variance that we estimate occurre d solely due to the shift to a monthly reporting period in January 1993. We define adjusted income for the 1993-1997 period as

$$
Y A_{h t}=\alpha_{1 t}+\beta_{t} X_{h t}+\left\{\sigma_{t} / \exp \left(\pi_{5}\right)\right\} \hat{\epsilon}_{h t} \quad t=97,98, \ldots, 156 .
$$

Here $\hat{\epsilon}_{h t}$ is the estimated residual from equation (1) and $\pi_{5}$ is our estimate from equation (2) of the increase in the $\log$ of the residual standard deviation due to the switch to monthly income reporting. The scale factors $\exp \left(\pi_{5}\right)$ are $1.179,1.446,1.222$, and 1.045 for worker-heade d households, farm households, mixed worker-farmer, and pensioner households, respectively.

A problem we confront is that a representative sample of the selfemployed was not obtained in the pre-1993 surveys. Representation of this group in the pre-1993 data is too small to obtain reliable estimates of the group- and time-specific residual variances. Besides, we could not be sure of the extent to which any change in variance for this group in 1993-1997 is due to the shift to monthly reporting versus increased representativenes $\mathrm{s}$ of the self-employed sample. Thus, we simply assume the same scale factor for the self-employed as we do for workers (1.179). In any case, it turns out that our results on changes in inequality are not very sensitive to how we treat the self-employed, because they constitute only about $5 \%$ to $6 \%$ of the sample.

We also adjust the consumption data using the same procedure. The estimated scale factors for consumption are 1.108, 1.149, 1.118, and 1.086 for worker-headed households, farm households, mixed worker-farmer, and pensioner-heade d households, respectively. As expected, these are lower than the income adjustment factors and are similar across different groups. For pensioner households, the jump in consumption variability is greater than the jump in income variability with the switch to monthly reporting. Although these households have more stable month-to-month income streams than other households, there is no obvious reason to expect their month-to-month variability in tastes for consumption to be lower. Finally, we also adjust the consumption data for the self-employe $d$ using the same scale factor we used for workers. 